\title{
Protic and Nonprotic Ionic Liquids in Polar Diels-Alder Reactions Using Properly Substituted Heterocycles and Carbocycles as Dienophiles. A DFT study
}

\author{
Pedro M. E. Mancini, Carla M. Ormachea, \\ Claudia D. Della Rosa, María N. Kneeteman and \\ Luis R. Domingo
}

Additional information is available at the end of the chapter

http://dx.doi.org/10.5772/51656

\section{Introduction}

The Diels-Alder (D-A) reaction is one of the most useful processes in preparative organic chemistry. Its potential in heterocyclic chemistry and natural products synthesis is very well known. It provides the chemist with one of his best tool for the preparation of cyclic compounds having a six-membered ring. The process is in one step inter or intramolecular from a diene and dienophile bearing an almost unlimited number of variants. It worth noting that these variants exist not only in the substitution of the reaction component but also in the electronic nature of these dienes and dienophiles. (Carruthers W, 1990; Fringelli F. et al 2002)

The D-A reaction has remained as one of the most powerful organic transformations in chemical synthesis, particularly in obtaining polycyclic rings. With the potential of forming carbon-carbon, carbon-heteroatom and heteroatom-heteroatom bonds, the reaction underlies the synthesis of diverse carbo- and heterocycle compounds. (Corey, 2002)

The design and discovery of ionic liquids (ILs) displaying a melting point lower than $100^{\circ} \mathrm{C}$, mainly room temperature ionic liquids (RTILs), have been the subject of considerable research efforts over the past decade RTILs have attracted considerable attention because these are expected to be ideal solvents to provide novel reactions in green chemistry (Hitchcock, et al, 1986; Welton, 1999). The interest in this class of molecules arises from their use as liquid media for a variety of chemical transformations specially D-A reactions, as substitutes of organic molecular solvents. ILs has importance due to their unique properties. Thus, this 
class of molecules is increasingly employed in organic chemistry, material sciences and physical chemistry (Wasserscheid \& Keim, 2000; Welton, 1999). An IL is a salt -substance composed exclusively of cations and anions-, and this fact differentiates them from simple ionic solutions, in which ions are dissolved in a molecular medium. They are also different from inorganic molten salts because their melting points are lower than $100{ }^{\circ} \mathrm{C}$ (most of them exist in liquid form at or near room temperature).

RTILs exhibit a variety of desirable properties, such as negligible vapor pressure, which makes them interesting for various applications. In particular, the option of fine-tuning chemical and physical properties by an appropriate choice of cations and anions has stimulated much of the current excitement with respect to these compounds and has led to the term "design solvents". ILs have high solvation ability for a wide variety of polar, non polar, organic and inorganic molecules as well as organometallic compounds. Moreover, the possibility of changing their properties allowing the selective salvation of solvents and thus control the mutual miscibility of particular organic compounds such as for instance alcohols and water. As a consequence, the characterization of the properties of different classes of ILs used as solvent for specific applications and for chemical reactions and catalysis, have been intensively investigated (Mancini, P.M.E., et al, 2012).

In base to their ionic nature, the structure of ILs incorporates different level of complexity. First and in order to maintain local electro neutrality, the high-charge density parts of cations and anions must create a three-dimensional network where the nearest neighbors of a given ion are of opposite sign. Second, the low-charge density residues that are often presents in the ions (generally as alkyl side chain) are segregated from the polar network, forming non polar domains. This nano-segregation/structuration between polar and non polar regions, first predicted by molecular dynamics simulation studies and later corroborated by diffraction techniques, implies the existence of differentiated and complex interactions not only in pure ionic liquid but also in their mixtures with molecular solutes or even other ionic liquids.

The imidazolium ILs were used to investigate the influence of the alkyl chain length and the presence of functional group on the cation on the polarity and the three Kamlet and Taft parameters $\left(\pi^{*}, \alpha\right.$, and $\beta$ ) measured the solvent dipolarity/polarizability, hydrogen-bond donating (HBD) acidity and hydrogen-bond accepting (HBA) basicity. The results shown that the length of the alkyl chain on the cation has a significant influence on polarizability and on HBD, but only a small influence on HBA and $\pi^{*}$, indicating that in these type of IL's, HBD is a major contributor to polarity.

In the last years we reported the electrophilic behavior of different aromatic heterocyclopentadienes properly mono and disubstituted with an electron-withdrawing group such as nitro or carboxylate in their exposure to different dienes under thermal conditions, using molecular solvents and ionic liquids, respectively. Moreover, we use as dienophile in this type of polar D-A reactions (P-DA) with normal electron demand, nitrotosylindoles, nitrobenzofuranes and nitrobenzothiophenes, properly substituted.

In general, these reactions are domino processes which are initialized by a P-DA reaction to give the formal [4+2] cycloadduct, which undergo an irreversible elimination of nitrous 
acid; this elimination is the factor responsible for the feasibility of the overall process. An alternative way is the hetero D-A reaction which takes place when some thiophene derivatives act as electrophiles. This last behavior is probably due to the improved aromatic character of these heterocycles.

For P-DA reactions one of the most interesting aspects is its solvent dependence. Moreover, in recent years, these reactions have been subject of several studies in order to enhance the reactivity. For specific P-DA reactions was demonstrated that the aqueous solutions have remarkable increase in reactivity and selectivity, and these results were discussed in terms of hydrogen-bond (HB) formation. Protic ionic liquids (PILs) with similar properties to water, such as being highly ordered media and good hydrogen bonding donor, have also been shown to have potential influence the outcome of P-DA reactions. Also, in this direction it is interesting discuss which is the influence on these reactions of non protic ionic liquids.

Due to our interest in the cycloaddition chemistry of substituted aromatic heterocycles with electron-withdrawing groups, we have reported that 2- and 3-nitrotosylpyrroles, 2nitrofurane, 2- and 3-nitrothiophenes, 1-tosyl-3-nitroindole, 2-nitrobenzofurane, 5- y 8-nitroquinolines and 1-nitronaphtalene, react as electrophiles in normal electron demand DA reaction (Biolatto, B., et al, 2001) (Della Rosa, C., et al, 2004, 2005, 2007,2010, 2011; Brasca, R., et al, 2010, 2011; Cancian, S., et al, 2010; Paredes, E., et al, 2007). These dienophiles were exposed to different dienes strongly, moderately and poorly activated under thermal conditions using molecular solvents as reaction media and in the same cases using PILs. In these reactions, the best results were obtained with the PILs and with chloroform as molecular solvent, due to its potential character HBD which could be influence the reactivity of the reaction systems. The participation of $N$-tosyl-nitropyrroles in cycloaddition reactions made possible a one spot simple indole synthesis.

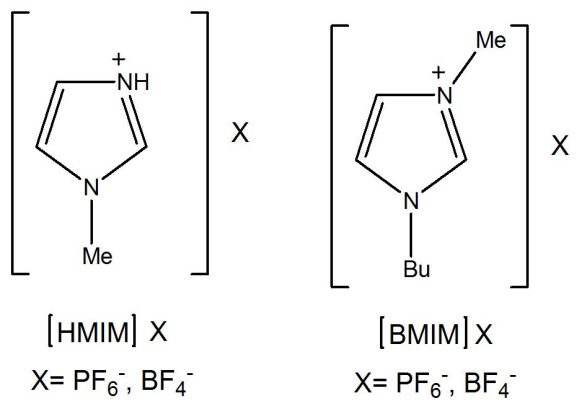

For to analyze the influence of room temperature ionic liquids (RTILs) in this type of polar cycloaddition reactions in which the dienophiles are relatively poor, ethylammoniun nitrate (EAN), 1-methylimidazolium tetrafluoroborate ([HMIM] $\left.\left[\mathrm{BF}_{4}\right]\right)$, and 1-methylimidazolium hexafluorophosphate $\left([\mathrm{HMIM}]\left[\mathrm{PF}_{6}\right]\right)$, 1- $n$-butyl-3-methylimidazolium tetrafluoroborate 
([BMIM] $\left.\left[\mathrm{BF}_{4}\right]\right)$ and 1-n-butyl-3-methylimidazolium hexafluorophosphate ([BMIM][PF 6$\left.]\right)$ were selected as reaction media. To explore the normal electron demand D-A dienophilicity of the proposed dienophiles we choose isoprene, 1-trimethylsilyloxy-1,3-butadiene, and 1methoxy-3-trimethylsilyloxy-1,3-butadiene (Danishefsky diene) as dienes.

In general, in all cases studied the presences of ILs have two effects. On one hand improved the yields in reaction conditions softer than those when we used molecular solvents. Moreover manifest a clear tendency to the aromatization of adducts. In particular, when 2- and 3nitrothiophene reacts in thermal conditions with isoprene in a molecular solvent we observed the corresponding hetero D-A adduct, however if an IL is the reaction media the reactions follow the normal D-A curse.

Considering that microwave irradiation has been used to enhance organic reactions in which an ionic liquid is used as the solvent, we have realized some experiences using a combination of microwave and PILs. In this case we noted that the microwave plus PILs constituted a synergetic mixture with strong effects on the reaction yields. ILs absorbed microwave irradiation extremely well and transfer energy rapidly by ionic conduction. At this point of the study we suppose that microwave irradiation has a major effect in a special range of energy activation barriers $(\Delta \mathrm{E})$. When the reaction $\Delta \mathrm{E}$ is too low, the presence of microwave radiation is not especially important, and if the value is extremely high, this irradiation would not take effect.

Part of this work is specifically concerned with theoretically studies using DFT methods. We try to obtain information about the factors affecting reactivity and selectivity. Previous studies have been developed in this type of calculation including one molecule of the ILs corresponding cation coordinated with the dienofile. In this new generation of theoretical studies the aim is to get a better solvatation model including in the system some molecules (in this case, IL's cations and anions) obtaining a "solvent box" which involves the reactive molecule like a $3 \mathrm{D}$ electrostactic network.

\section{Main Objetives}

The aim of the present review is twofold. The first purpose is to analyze the influence of RTILs protic and nonprotic in polar cycloaddition reactions in which the dienophiles are relatively poor -aromatic carbocycles and heterocycles compounds substituted with electron withdrawing groups-. For this purpose alkylimidazolium and dialkylimmidazolium-based ILs have been selected because the differences in their HBD acidity. The second purpose concerned with theoretically studies using DFT methods. We try to obtain information about reaction mechanisms which would be affect reactivity and selectivity. In general, it would be possible demonstrated that the ILs solvent effect in these reactions is in general determined by the solvent hydrogen bond donation ability. 


\section{Results and Discussion}

With the purpose of comparison and reference, we have taken in account the results obtained when the aromatic substrates heterocycles and carbocycles proposed, adequately substituted by electron with-drawing groups, take part in cycloaddition reactions with diverse dienes of nucleophilicity variable, development in molecular solvents or in PILs. These results will be compared with those reached when the cycloaddition reactions are developed in nonprotic ILs. If it is necessary the cited compilation will be included in the corresponding tables of results, looking for an appropriate comprehension of the influence of the reaction media in this type of Diels-Alder reactions.

\subsection{Monocyclic five membered and benzofused five membered nitroheteroaromatic compounds, as dienophiles}

The study of dienophilic character of substituted nitroaromatic heterocycles in the presence of ILs was carried out employing 2-nitrofuran (1a), 2,5-dimethyl-3-nitrofuran (1b), 1-tosyl-2nitropyrrole (2a), 1-tosyl-3-nitropyrrole (2b), 2- and 3- nitrothiophene (3a, 3b), 1-tosyl-3-nitroindol (4) and 2-nitrobenzofurane (5). In addition, isoprene (6), 1- trimethylsiloxy-1,3butadiene (7), 1-methoxy-3-trimethylsiloxy-1,3-butadiene (Danishefsky's diene) (8) were selected as dienes, covering an attractive spectre of nucleophilic character (Figure 1).

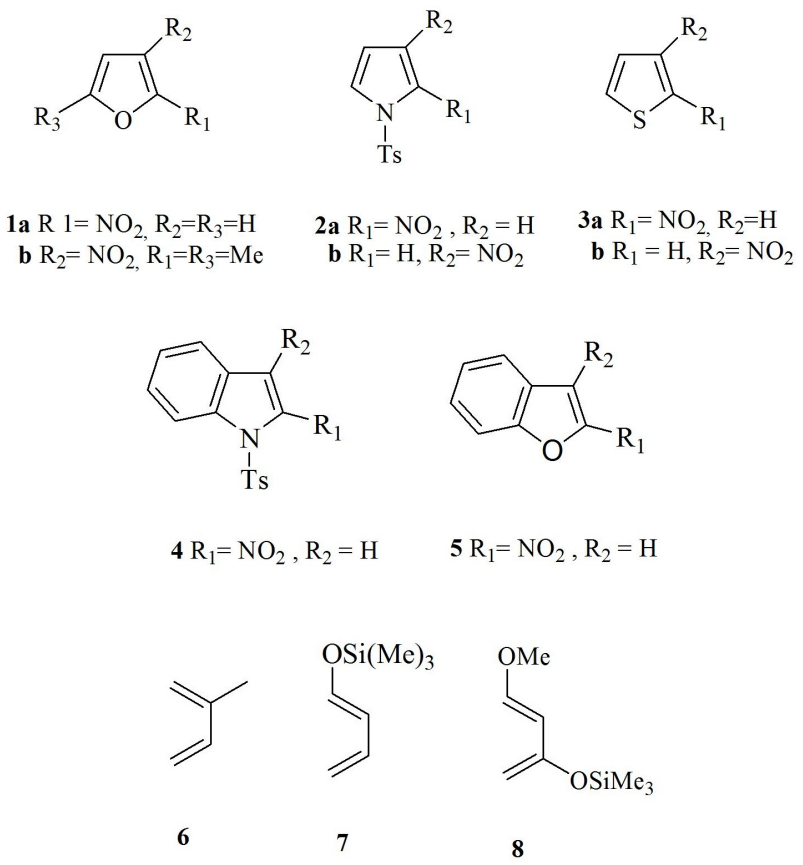

Figure 1. Dienophiles and dienes used in the different experiences. 
When 1a was reacted with the less reactive isoprene 6 in a sealed ampoule at $60^{\circ} \mathrm{C}$ for $24 \mathrm{~h}$ using $[\mathrm{BMIM}]\left[\mathrm{BF}_{4}\right]$ or $[\mathrm{BMIM}]\left[\mathrm{PF}_{6}\right]$ as solvent, respectively, the reactions proceeded to produce a mixture of isomeric benzofurans $10 \mathrm{a}$ and $10 \mathrm{~b}(1: 1)$ as the principal products with reasonable yield and dihydrobenzofurans $9 \mathrm{a}$ and $9 \mathrm{~b}$ (1:1) (Figure 2). If the time of the reaction increased to $48 \mathrm{~h}$ we observe a 1:1 mixture of isomeric benzofurans 10a and 10b in reasonable yield and traces of the isomeric dihydrobenzofurans $9 \mathrm{a}$ and $9 \mathrm{~b}$. Similar results were observed when the reaction was development in EAN and $[\mathrm{HMIM}]\left[\mathrm{BF}_{4}\right]$ although with these solvents the yields were majors (Table 1).

In the same manner, in the case of 1-tosyl-2-nitropyrrole 2a, it reacted with isoprene in $[\mathrm{BMIM}]\left[\mathrm{BF}_{4}\right]$ or $[\mathrm{BMIM}]\left[\mathrm{PF}_{6}\right]\left(60^{\circ} \mathrm{C}, 24 \mathrm{~h}\right)$ furnishing indole isomers $12 \mathrm{a}, \mathrm{b}$ as the principal products in moderate yield, and dihydroindole isomers 11a,b. All addition products showed extrusion of the nitro group as nitrous acid. (Della Rosa, et al, 2007) (Table 1)

In contrast with the above mentioned behavior, when 2-nitrothiophene 3a was tested with 6, it gave traces of pyrrolyl-thiophene 13 formed by a heterocycloaddition followed by thermal rearrangement. (Della Rosa, et al, 2004) (Figure 2, Table 1). This unexpected behavior was also found with other compounds with stronger aromatic character. The observed low yield in this reaction would be attributed to the interaction between the nitro group and the ILs (Table 1).

\begin{tabular}{|c|c|c|c|c|}
\hline Entry & Dienophile $^{a}$ & Conditions $^{b}$ & Products & Yield (\%) \\
\hline 1 & $1 a$ & EAN & $9 a, b ; 10 a, b$ & $40 ; 17$ \\
\hline 2 & & {$[\mathrm{HMIM}]\left[\mathrm{BF}_{4}\right]$} & $9 a, b ; 10 a, b$ & 30: 15 \\
\hline 3 & & {$[\mathrm{HMIM}]\left[\mathrm{PF}_{6}\right]$} & $9 a, b ; 10 a, b$ & $28 ; 14$ \\
\hline 4 & & {$[\mathrm{BMIM}]\left[\mathrm{BF}_{4}\right]$} & $9 a, b ; 10 a, b$ & $25 ; 05$ \\
\hline 5 & & {$[\mathrm{BMIM}]\left[\mathrm{PF}_{6}\right]$} & $9 a, b ; 10 a, b$ & $26 ; 05$ \\
\hline 6 & $2 a$ & EAN & $11 a, b ; 12 a, b$ & $40 ; 12$ \\
\hline 7 & & {$[\mathrm{HMIM}]\left[\mathrm{BF}_{4}\right]$} & $11 a, b ; 12 a, b$ & $30 ; 10$ \\
\hline 8 & & {$[\mathrm{HMIM}]\left[\mathrm{PF}_{6}\right]$} & $11 a, b ; 12 a, b$ & $28 ; 09$ \\
\hline 9 & & {$[\mathrm{BMIM}]\left[\mathrm{BF}_{4}\right]$} & $11 a, b ; 12 a, b$ & $20 ; 04$ \\
\hline 10 & & {$[\mathrm{BMIM}]\left[\mathrm{PF}_{6}\right]$} & $11 a, b ; 12 a, b$ & $21 ; 05$ \\
\hline 11 & $3 a$ & EAN & 13 & 18 \\
\hline 12 & & {$[\mathrm{HMIM}]\left[\mathrm{BF}_{4}\right]$} & 13 & 12 \\
\hline 13 & & {$[\mathrm{HMIM}]\left[\mathrm{PF}_{6}\right]$} & 13 & 12 \\
\hline 14 & & {$[\mathrm{BMIM}]\left[\mathrm{BF}_{4}\right]$} & 13 & Traces \\
\hline 15 & & {$[\mathrm{BMIM}]\left[\mathrm{PF}_{6}\right]$} & 13 & Traces \\
\hline \multicolumn{5}{|c|}{$\begin{array}{l}{ }^{a} \text { Diene/dienophile ratio } 12: 1 \\
\text { b Reaction's time } 24 \mathrm{~h} \text {, reaction's temperature } 60^{\circ} \mathrm{C} \text {. } \\
\text { ' Based on consumed dienophile. }\end{array}$} \\
\hline
\end{tabular}

Table 1. Diels-Alder reactions of 2-nitroheterocycles with isoprene. 


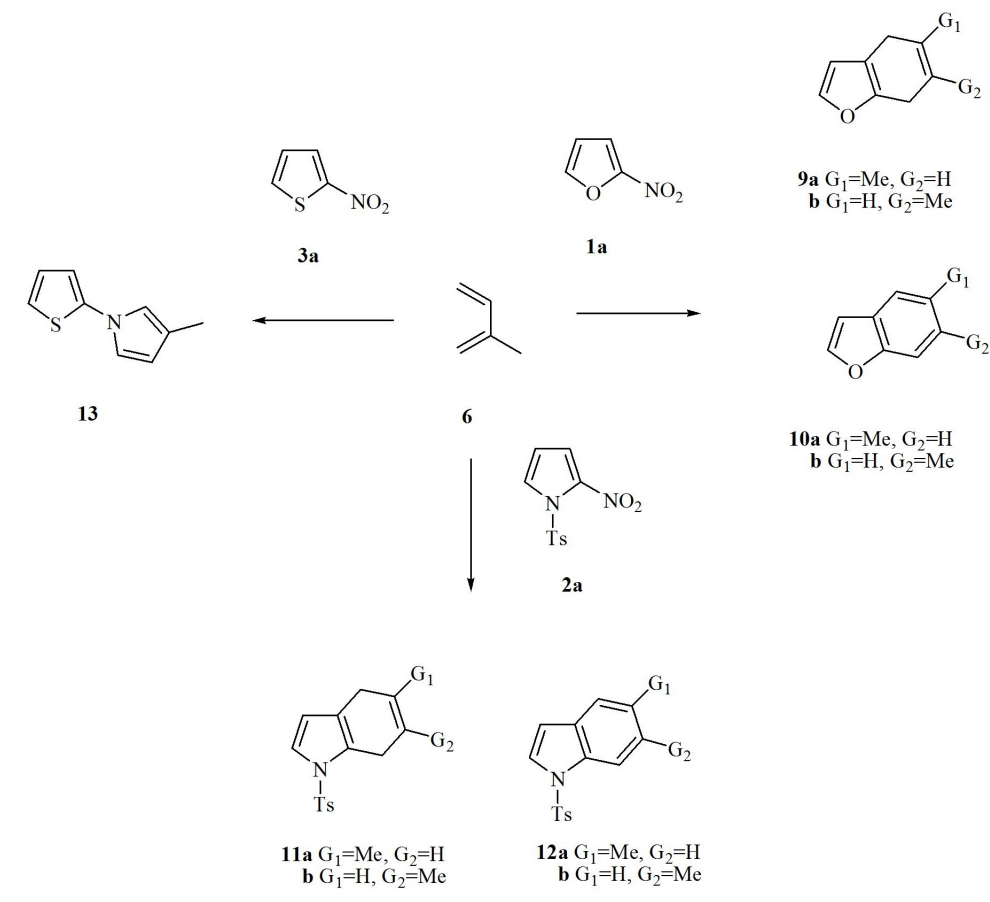

Figure 2. Diels-Alder reactions of aromatic 2- nitroheterocycles with isoprene.
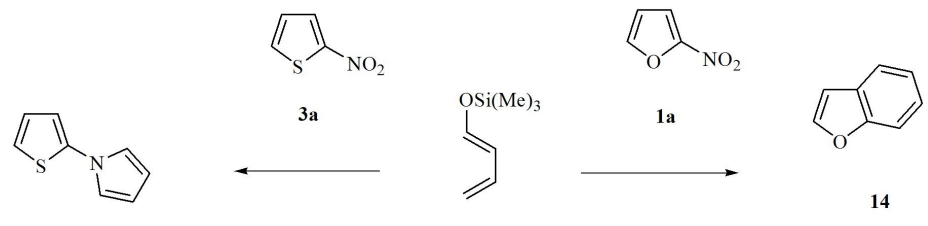

16

7

14

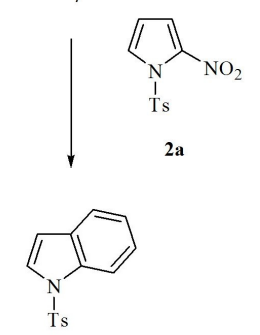

15

Figure 3. Diels-Alder reactions of aromatic 2- nitroheterocycles with diene 7. 
The reactions of 1a with 1-trimethylsilyloxy-1,3-butadiene using [BMIM] $\left[\mathrm{BF}_{4}\right]$ and [BMIM] $\left[\mathrm{PF}_{6}\right]$, respectively, as solvents, in seals ampoule $\left(60^{\circ} \mathrm{C}, 24 \mathrm{~h}\right)$, offered in all cases good yield in benzofuran 14 . The yields were lower that those obtained with EAN, $[\mathrm{HMIM}]\left[\mathrm{BF}_{4}\right]$ and $[\mathrm{HMIM}]\left[\mathrm{PF}_{6}\right]$, as solvent. On the other hand, the reaction of $2 \mathrm{a}$ with this diene produced $\mathrm{N}$ tosylindole 15, with reasonable yield little lower when PILs were used. In the reaction of 3a with 7 we observed again traces of the corresponding hetero Diels-Alder product 16 followed the same trend that the reaction with isoprene (Figure 3)(Table 2).

\begin{tabular}{|c|c|c|c|c|}
\hline Entry & Dienophile $^{a}$ & Conditions $^{b}$ & Products & Yield (\%) \\
\hline 1 & $1 a$ & EAN & 14 & 62 \\
\hline 2 & & {$[\mathrm{HMIM}]\left[\mathrm{BF}_{4}\right]$} & 14 & 58 \\
\hline 3 & & {$[\mathrm{HMIM}]\left[\mathrm{PF}_{6}\right]$} & 14 & 57 \\
\hline 4 & & {$[\mathrm{BMIM}]\left[\mathrm{BF}_{4}\right]$} & 14 & 42 \\
\hline 5 & & {$[\mathrm{BMIM}]\left[\mathrm{PF}_{6}\right]$} & 14 & 43 \\
\hline 6 & $2 a$ & EAN & 15 & 63 \\
\hline 7 & & {$[\mathrm{HMIM}]\left[\mathrm{BF}_{4}\right]$} & 15 & 51 \\
\hline 8 & & {$[\mathrm{HMIM}]\left[\mathrm{PF}_{6}\right]$} & 15 & 52 \\
\hline 9 & & {$[\mathrm{BMIM}]\left[\mathrm{BF}_{4}\right]$} & 15 & 39 \\
\hline 10 & & {$[\mathrm{BMIM}]\left[\mathrm{PF}_{6}\right]$} & 15 & 38 \\
\hline 11 & $3 a$ & EAN & 16 & 15 \\
\hline 12 & & {$[\mathrm{HMIM}]\left[\mathrm{BF}_{4}\right]$} & 16 & 12 \\
\hline 13 & & {$[\mathrm{HMIM}]\left[\mathrm{PF}_{6}\right]$} & 16 & 12 \\
\hline 14 & & {$[\mathrm{BMIM}]\left[\mathrm{BF}_{4}\right]$} & 16 & Traces \\
\hline 15 & & {$[\mathrm{BMIM}]\left[\mathrm{PF}_{6}\right]$} & 16 & Traces \\
\hline \multicolumn{5}{|c|}{$\begin{array}{l}\text { a Diene/dienophile ratio } 3: 1 \\
{ }^{b} \text { Reaction's time } 24 \mathrm{~h} \text {, reaction's temperature } 60^{\circ} \mathrm{C} \text {. } \\
\text { ' Based on consumed dienophile. }\end{array}$} \\
\hline
\end{tabular}

Table 2. Diels-Alder reactions of 2- nitroheterocycles with 1-trimethylsilyloxy-1,3-butadiene.

The reaction of Danishefsky's diene with 1a using the nonprotic ILs cited in the before paragraphs yielded 5-hydroxyibenzofuran 17 in reasonable yield. Similarly to the reactions with isoprene and 1-trimethylsilyloxy-1,3-butadiene, the best yield was observed with EAN (Mancini, P.M.E., et al, 2011).In turn the reactions of 2a with diene 8 developed in these nonprotic ILs offered 1-tosyl-5-hydroxyindole in good yield. However, in the reactions of 3a with this diene and the neoteric solvents, we observed only traces of the aromatic product 19. The results derived from the aromatization of the nitro-adducts promoted by the loss of the nitro and methoxyl groups as nitrous acid and methanol, respectively. The intermediate that suffered nitrous acid extrusion and retained the methoxy group was not detected in any 
case. In all cases the presence of PIL's as reaction media, improve the yields respect to the use of nonpolar ILs (Figure 4) (Table 3).

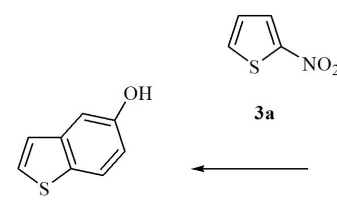

19

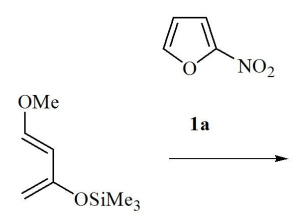

8

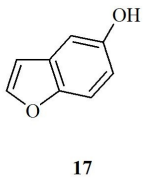

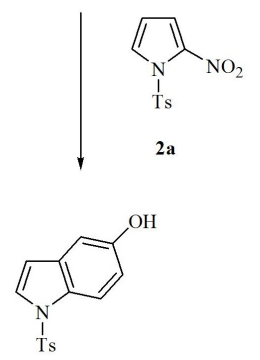

18

Figure 4. Diels-Alder reactions of aromatic 2- nitroheterocycles with Danishefsky's diene.

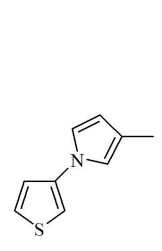

21

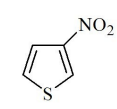

$3 \mathbf{b}$
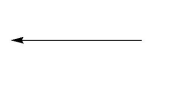

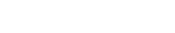

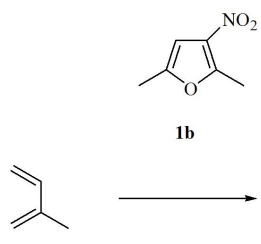

6

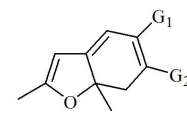

20a $\mathrm{G}_{1}=\mathrm{Me}, \mathrm{G}_{2}=\mathrm{H}$ b $\mathrm{G}_{1}=\mathrm{H}, \mathrm{G}_{2}=\mathrm{Me}$

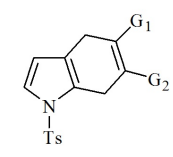

$\begin{aligned} \text { 11. } \mathrm{G}_{1} & =\mathrm{Me}, \mathrm{G}_{2}=\mathrm{H} \\ \text { b } \mathrm{G}_{1} & =\mathrm{H}, \mathrm{G}_{2}=\mathrm{Me}\end{aligned}$<smiles>O=[N+]([O-])c1ccc(I)cc1</smiles>

$2 \mathbf{b}$

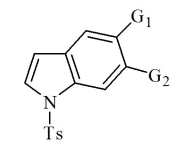
$\begin{aligned} \text { 12. } \mathrm{G}_{1} & =\mathrm{Me}, \mathrm{G}_{2}=\mathrm{H} \\ \text { b } \mathrm{G}_{1} & =\mathrm{H}, \mathrm{G}_{2}=\mathrm{Me}\end{aligned}$

Figure 5. Diels-Alder reactions of aromatic 3- nitroheterocycles with isoprene. 


\begin{tabular}{|c|c|c|c|c|}
\hline Entry & Dienophile $^{a}$ & Conditions $^{\mathrm{b}}$ & Products & Yield (\%) \\
\hline 1 & $1 \mathrm{a}$ & EAN & 17 & 65 \\
\hline 2 & & {$[\mathrm{HMIM}]\left[\mathrm{BF}_{4}\right]$} & 17 & 59 \\
\hline 3 & & {$[\mathrm{HMIM}]\left[\mathrm{PF}_{6}\right]$} & 17 & 60 \\
\hline 4 & & {$[\mathrm{BMIM}]\left[\mathrm{BF}_{4}\right]$} & 17 & 40 \\
\hline 5 & & {$[\mathrm{BMIM}]\left[\mathrm{PF}_{6}\right]$} & 17 & 38 \\
\hline 6 & $2 a$ & EAN & 18 & 57 \\
\hline 7 & & {$[\mathrm{HMIM}]\left[\mathrm{BF}_{4}\right]$} & 18 & 55 \\
\hline 8 & & {$[\mathrm{HMIM}]\left[\mathrm{PF}_{6}\right]$} & 18 & 54 \\
\hline 9 & & {$[\mathrm{BMIM}]\left[\mathrm{BF}_{4}\right]$} & 18 & 42 \\
\hline 10 & & {$[\mathrm{BMIM}]\left[\mathrm{PF}_{6}\right]$} & 18 & 41 \\
\hline 11 & $3 a$ & EAN & 19 & 42 \\
\hline 12 & & {$[\mathrm{HMIM}]\left[\mathrm{BF}_{4}\right]$} & 19 & 36 \\
\hline 13 & & {$[\mathrm{HMIM}]\left[\mathrm{PF}_{6}\right]$} & 19 & 35 \\
\hline 14 & & {$[\mathrm{BMIM}]\left[\mathrm{BF}_{4}\right]$} & 19 & 22 \\
\hline 15 & & {$[\mathrm{BMIM}]\left[\mathrm{PF}_{6}\right]$} & 19 & 21 \\
\hline \multicolumn{5}{|c|}{$\begin{array}{l}\text { a Diene/dienophile ratio } 2: 1 \\
\text { b Reaction's time } 24 \mathrm{~h} \text {, reaction's temperature } 60^{\circ} \mathrm{C} \text {. } \\
\text { ' Based on consumed dienophile. }\end{array}$} \\
\hline
\end{tabular}

Table 3. Diels-Alder reactions of 2-nitroheterocycles with Danishefsky's diene.

When 1-tosyl-3-nitropyrrole $2 \mathrm{~b}$ was tested with isoprene as diene and [BMIM] $\left[\mathrm{BF}_{4}\right],[\mathrm{BMIM}]$ $\left[\mathrm{PF}_{6}\right]$ as solvent $\left(60^{\circ} \mathrm{C}, 24 \mathrm{~h}\right)$, the reactions afforded a mixture of regioisomeric cycloadducts previously informed: $11 \mathrm{a}, \mathrm{b} ; 12 \mathrm{a}, \mathrm{b}$. In the same direction and due to the impossibility of obtaining 3-nitrofuran, when 2,5-dimethyl-3-nitrofuran $1 \mathrm{~b}$ was exposed to 6 , the D-A reaction $\left(60^{\circ} \mathrm{C} / 24 \mathrm{~h}\right)$ in the nonprotic ILs proceeded to furnish the mixture of regioisomers $20 \mathrm{a}$ and $20 \mathrm{~b}$. Once again the reaction of $3 \mathrm{~b}$, and this diene development in ILs yielded only traces of the pyrrole derivative 21 in the same manner that $3 \mathrm{a}$, formed by a heterocycloaddition followed by thermal rearrangement (Figure 5) (Table 4). In all cases the yields of these reactions in presence of the PILs are better

\begin{tabular}{|c|c|c|c|c|}
\hline Entry & Dienophile $^{a}$ & Conditions $^{b}$ & Products & Yield (\%) \\
\hline 1 & $1 b$ & EAN & $20 a, b$ & $38 ; 15$ \\
\hline 2 & & {$[\mathrm{HMIM}]\left[\mathrm{BF}_{4}\right]$} & $20 a, b$ & 30: 15 \\
\hline 3 & & {$[\mathrm{HMIM}]\left[\mathrm{PF}_{6}\right]$} & $20 a, b$ & $28 ; 14$ \\
\hline 4 & & {$[\mathrm{BMIM}]\left[\mathrm{BF}_{4}\right]$} & $20 a, b$ & $25 ; 05$ \\
\hline 5 & & {$[\mathrm{BMIM}]\left[\mathrm{PF}_{6}\right]$} & $20 a, b$ & $26 ; 05$ \\
\hline 6 & $2 b$ & EAN & $11 a, b ; 12 a, b$ & $41 ; 12$ \\
\hline
\end{tabular}




\begin{tabular}{|c|c|c|c|}
\hline Entry Dienophile & Conditions $^{b}$ & Products & Yield (\%) \\
\hline 7 & {$[\mathrm{HMIM}]\left[\mathrm{BF}_{4}\right]$} & $11 a, b ; 12 a, b$ & $30 ; 10$ \\
\hline 8 & {$[\mathrm{HMIM}]\left[\mathrm{PF}_{6}\right]$} & $11 a, b ; 12 a, b$ & $29 ; 09$ \\
\hline 9 & {$[\mathrm{BMIM}]\left[\mathrm{BF}_{4}\right]$} & $11 a, b ; 12 a, b$ & $20 ; 04$ \\
\hline 10 & {$[\mathrm{BMIM}]\left[\mathrm{PF}_{6}\right]$} & $11 a, b ; 12 a, b$ & $21 ; 05$ \\
\hline $3 b$ & EAN & 21 & 15 \\
\hline 12 & {$[\mathrm{HMIM}]\left[\mathrm{BF}_{4}\right]$} & 21 & 11 \\
\hline 13 & {$[\mathrm{HMIM}]\left[\mathrm{PF}_{6}\right]$} & 21 & 11 \\
\hline 14 & {$[\mathrm{BMIM}]\left[\mathrm{BF}_{4}\right]$} & 21 & Traces \\
\hline 15 & {$[\mathrm{BMIM}]\left[\mathrm{PF}_{6}\right]$} & 21 & Traces \\
\hline \multicolumn{4}{|c|}{$\begin{array}{l}\text { a Diene/dienophile ratio } 3: 1 \\
\text { b Reaction's time } 24 \mathrm{~h} \text {, reaction's temperature } 60^{\circ} \mathrm{C} \text {. } \\
\text { ' Based on consumed dienophile. }\end{array}$} \\
\hline
\end{tabular}

Table 4. Diels-Alder reactions of 3- nitroheterocycles with isoprene.

Exposure of 1-tosyl-3-nitropyrrole $2 \mathrm{~b}$ to dienes 7 and 8 in the presence of [BMIM][BF $\left.{ }_{4}\right]$, $[\mathrm{BMIM}]\left[\mathrm{PF}_{6}\right]$ yielded 1-tosyl-indole 15 and 1-tosyl-indole-6-ol 23, respectively with moderate yield. At the same time, mononitrated substrate $3 b$ in its reaction with diene 7 afforded traces of the pyrrolyl derivative 22 . However, $3 \mathrm{~b}$ did not undergo cycloaddition with diene 8. Probably this behavior is a consequence of the special reactivity of this substrate connected with its aromaticity (Figures 6 and 7) (Tables 5 and 6).

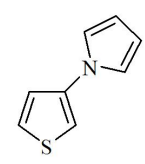

22
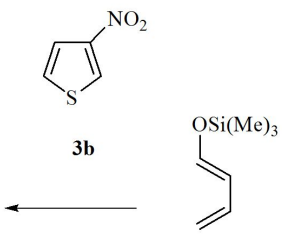

7
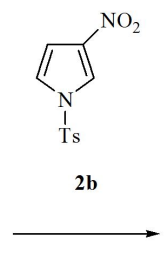<smiles>[AlH2]n1ccc2ccccc21</smiles>

15

Figure 6. Diels-Alder reactions of aromatic 3- nitroheterocycles with diene 7.

\begin{tabular}{ccccc}
\hline Entry & Dienophile $^{\mathbf{a}}$ & Conditions $^{\mathbf{b}}$ & Products & Yield (\%) \\
\hline 1 & $\mathbf{2 b}$ & $\mathrm{EAN}$ & $\mathbf{1 5}$ & 61 \\
\hline 2 & & {$[\mathrm{HMIM}]\left[\mathrm{BF}_{4}\right]$} & $\mathbf{1 5}$ & 51 \\
\hline 3 & {$[\mathrm{HMIM}]\left[\mathrm{PF}_{6}\right]$} & $\mathbf{1 5}$ & 50 \\
\hline 4 & & {$\left[\mathrm{BMIM}_{[}\right]\left[\mathrm{BF}_{4}\right]$} & $\mathbf{1 5}$ & 35 \\
\hline
\end{tabular}




\begin{tabular}{|c|c|c|c|c|}
\hline Entry & Dienophile $^{a}$ & Conditions $^{b}$ & Products & Yield $(\%)^{c}$ \\
\hline 5 & & {$[\mathrm{BMIM}]\left[\mathrm{PF}_{6}\right]$} & 15 & 36 \\
\hline 6 & $3 b$ & EAN & 22 & 12 \\
\hline 7 & & {$[\mathrm{HMIM}]\left[\mathrm{BF}_{4}\right]$} & 22 & 11 \\
\hline 8 & & {$[\mathrm{HMIM}]\left[\mathrm{PF}_{6}\right]$} & 22 & 11 \\
\hline 9 & & {$[\mathrm{BMIM}]\left[\mathrm{BF}_{4}\right]$} & 22 & Traces \\
\hline 10 & & {$[\mathrm{BMIM}]\left[\mathrm{PF}_{6}\right]$} & 22 & Traces \\
\hline \multicolumn{5}{|c|}{$\begin{array}{l}\text { a Diene/dienophile ratio } 3: 1 \\
\text { b Reaction's time } 24 \mathrm{~h} \text {, reaction's temperature } 60^{\circ} \mathrm{C} \text {. } \\
\text { c Based on consumed dienophile. }\end{array}$} \\
\hline
\end{tabular}

Table 5. Diels-Alder reactions of 3- nitroheterocycles with 7.

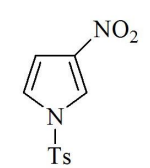

$\mathbf{2 b}$

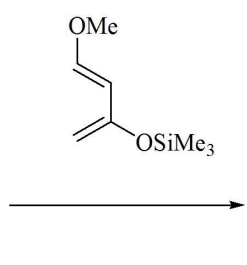

Figure 7. Diels-Alder reactions of aromatic 3- nitroheterocycles with Danishefsky's diene.

\begin{tabular}{|c|c|c|c|c|}
\hline Entry & Dienophile $^{a}$ & Conditions $^{b}$ & Products & Yield (\%) \\
\hline 1 & $2 b$ & EAN & 23 & 62 \\
\hline 2 & & {$[\mathrm{HMIM}]\left[\mathrm{BF}_{4}\right]$} & 23 & 55 \\
\hline 3 & & {$[\mathrm{HMIM}]\left[\mathrm{PF}_{6}\right]$} & 23 & 54 \\
\hline 4 & & {$[\mathrm{BMIM}]\left[\mathrm{BF}_{4}\right]$} & 23 & 43 \\
\hline 5 & & {$[\mathrm{BMIM}]\left[\mathrm{PF}_{6}\right]$} & 23 & 41 \\
\hline \multicolumn{5}{|c|}{$\begin{array}{l}\text { a Diene/dienophile ratio } 3: 1 \\
\text { b Reaction's time } 24 \mathrm{~h} \text {, reaction 's temperature } 60^{\circ} \mathrm{C} \text {. } \\
\text { ' Based on consumed dienophile. }\end{array}$} \\
\hline
\end{tabular}

Table 6. Diels-Alder reactions of 3- nitroheterocycles with 9.

\subsubsection{Nitroindole as dienophiles}

When 1-tosyl-3-nitroindole 4 was tested with isoprene as diene and [BMIM] $\left[\mathrm{BF}_{4}\right]$ or [BMIM] $\left[\mathrm{PF}_{6}\right]$ as solvent $\left(60^{\circ} \mathrm{C}, 24 \mathrm{~h}\right)$, the reactions afforded a mixture of regioisomeric cycloadducts $25 \mathrm{a}, \mathrm{b}$, as principal products in reasonable yield, and traces of the regioisomers $24 \mathrm{a}, \mathrm{b}$. On the 
other hand the reactions of 4 with the dienes 7 and 8 in these ILs produced N-tosylcarbazole 26 and the hydroxycarbazole 27 in reasonable good yield. In all cases the yields were lower than those obtained with PILs (EAN, $[\mathrm{HMIM}]\left[\mathrm{BF}_{4}\right]$ and $\left.[\mathrm{HMIM}]\left[\mathrm{PF}_{6}\right]\right)$ (Figure 8) (Table 7).

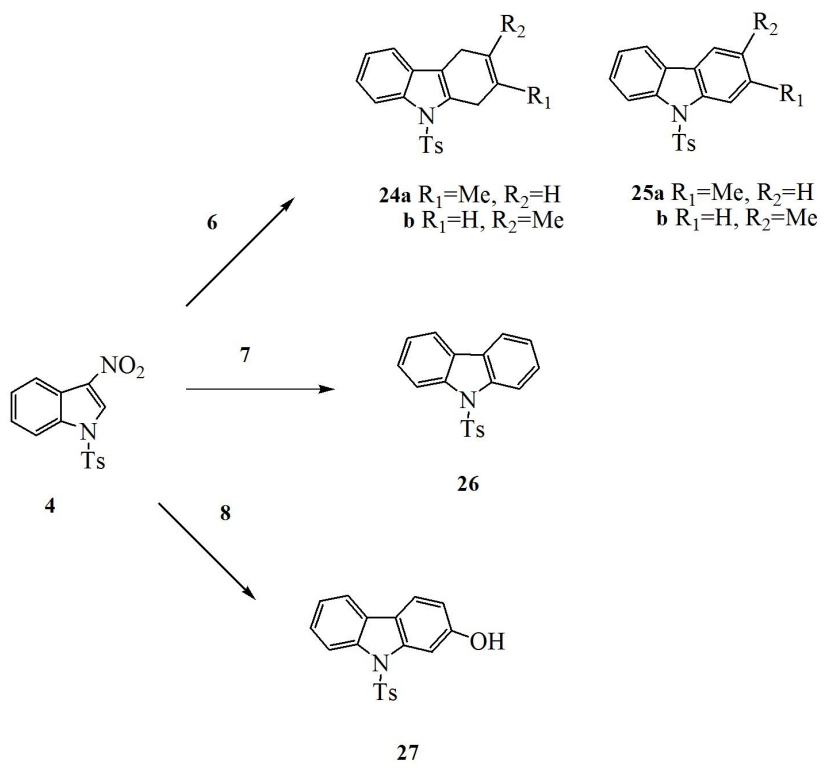

Figure 8. Diels-Alder reactions of 1-tosyl-3-nitroindol with dienes 6, 7 and 8 .

\begin{tabular}{|c|c|c|c|c|}
\hline Entry & Dienophile $^{a}$ & Conditions $^{b}$ & Products & Yield (\%) \\
\hline 1 & 6 & EAN & $24 a, b ; 25 a, b$ & $45 ; 05$ \\
\hline 2 & & {$[\mathrm{HMIM}]\left[\mathrm{BF}_{4}\right]$} & $24 a, b ; 25 a, b$ & 42: 03 \\
\hline 3 & & {$[\mathrm{HMIM}]\left[\mathrm{PF}_{6}\right]$} & $24 a, b ; 25 a, b$ & $42 ; 04$ \\
\hline 4 & & {$[\mathrm{BMIM}]\left[\mathrm{BF}_{4}\right]$} & $24 a, b, 25 a, b$ & $30 ; 02$ \\
\hline 5 & & {$[\mathrm{BMIM}]\left[\mathrm{PF}_{6}\right]$} & $24 a, b ; 25 a, b$ & $31 ; 02$ \\
\hline 6 & 7 & EAN & 26 & 62 \\
\hline 7 & & {$[\mathrm{HMIM}]\left[\mathrm{BF}_{4}\right]$} & 26 & 55 \\
\hline 8 & & {$[\mathrm{HMIM}]\left[\mathrm{PF}_{6}\right]$} & 26 & 56 \\
\hline 9 & & {$[\mathrm{BMIM}]\left[\mathrm{BF}_{4}\right]$} & 26 & 40 \\
\hline 10 & & {$[\mathrm{BMIM}]\left[\mathrm{PF}_{6}\right]$} & 26 & 41 \\
\hline 11 & 8 & EAN & 27 & 72 \\
\hline 12 & & {$[\mathrm{HMIM}]\left[\mathrm{BF}_{4}\right]$} & 27 & 65 \\
\hline 13 & & {$[\mathrm{HMIM}]\left[\mathrm{PF}_{6}\right]$} & 27 & 63 \\
\hline
\end{tabular}




\begin{tabular}{|c|c|c|c|}
\hline Entry Dienophile & Conditions $^{b}$ & Products & Yield (\%) \\
\hline 14 & {$[\mathrm{BMIM}]\left[\mathrm{BF}_{4}\right]$} & 27 & 51 \\
\hline 15 & {$[\mathrm{BMIM}]\left[\mathrm{PF}_{6}\right]$} & 27 & 48 \\
\hline $\begin{array}{l}\text { Diene/dienophile rat } \\
\text { Reaction's time } 24 \mathrm{~h} \\
\text { Based on consumed }\end{array}$ & $\begin{array}{l}3: 1 \\
\text { action's temp } \\
\text { hophile. }\end{array}$ & $50^{\circ} \mathrm{C}$ & \\
\hline
\end{tabular}

Table 7. Diels-Alder reactions of dienophile 4 with different dienes.

\subsubsection{2-NitroBenzofuran as dienophile}

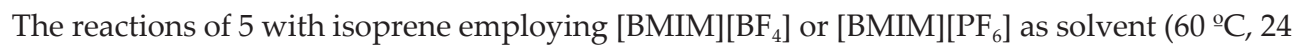
h) afforded the mixture of aromatic regioisomeric cycloadducts $28 \mathrm{a}, \mathrm{b}$ as principal products and traces of dihydrodibenzofurans $29 \mathrm{a}$ and 29b. On the other hand, reactions of 5 with 1-trimethylsilyloxy-1,3-butadiene $\left(60^{\mathrm{a}} \mathrm{c}, 24 \mathrm{~h}\right.$, [BMIM] $\left[\mathrm{BF}_{4}\right]$ and $\left.[\mathrm{BMIM}]\left[\mathrm{PF}_{6}\right]\right)$ yielded dibenzofuran 30 with loss of trimethylsilyloxy and nitro groups. The yield is good. In the same way, in the reaction of 2-nitrobenzofuran with the Danishefsky`s diene hidroxy aromatic cycloadduct 31 was obtained with very good yield and complete regioselectivity (Figure 9, Table 8). With these solvents the yields were lower than using PILs (EAN, $[\mathrm{HMIM}]\left[\mathrm{BF}_{4}\right]$ and $[\mathrm{HMIM}]\left[\mathrm{PF}_{6}\right]$ )

\begin{tabular}{|c|c|c|c|c|}
\hline Entry & Dieno $^{a}$ & Conditions $^{b}$ & Products & Yield (\%) \\
\hline 1 & 6 & EAN & $28 a, b ; 29 a, b$ & $42 ; 04$ \\
\hline 2 & & {$[\mathrm{HMIM}]\left[\mathrm{BF}_{4}\right]$} & $28 a, b ; 29 a, b$ & 38: 03 \\
\hline 3 & & {$[\mathrm{HMIM}]\left[\mathrm{PF}_{6}\right]$} & $28 a, b ; 29 a, b$ & $38 ; 04$ \\
\hline 4 & & {$[\mathrm{BMIM}]\left[\mathrm{BF}_{4}\right]$} & $28 a, b ; 29 a, b$ & $27 ; 02$ \\
\hline 5 & & {$[\mathrm{BMIM}]\left[\mathrm{PF}_{6}\right]$} & $28 a, b ; 29 a, b$ & $27 ; 02$ \\
\hline 6 & 7 & EAN & 30 & 58 \\
\hline 7 & & {$[\mathrm{HMIM}]\left[\mathrm{BF}_{4}\right]$} & 30 & 52 \\
\hline 8 & & {$[\mathrm{HMIM}]\left[\mathrm{PF}_{6}\right]$} & 30 & 51 \\
\hline 9 & & {$[\mathrm{BMIM}]\left[\mathrm{BF}_{4}\right]$} & 30 & 36 \\
\hline 10 & & {$[\mathrm{BMIM}]\left[\mathrm{PF}_{6}\right]$} & 30 & 35 \\
\hline 11 & 8 & EAN & 31 & 66 \\
\hline 12 & & {$[\mathrm{HMIM}]\left[\mathrm{BF}_{4}\right]$} & 31 & 59 \\
\hline 13 & & {$[\mathrm{HMIM}]\left[\mathrm{PF}_{6}\right]$} & 31 & 58 \\
\hline 14 & & {$[\mathrm{BMIM}]\left[\mathrm{BF}_{4}\right]$} & 31 & 45 \\
\hline 15 & & {$[\mathrm{BMIM}]\left[\mathrm{PF}_{6}\right]$} & 31 & 42 \\
\hline \multicolumn{5}{|c|}{$\begin{array}{l}\text { a Diene/dienophile ratio } 3: 1 \\
\text { b Reaction's time } 24 \mathrm{~h} \text {, reaction's temperature } 60^{\circ} \mathrm{C} \text {. } \\
\text { ' Based on consumed dienophile. }\end{array}$} \\
\hline
\end{tabular}

Table 8. Diels-Alder reactions of 2-nitrobenzofuran with different dienes. 


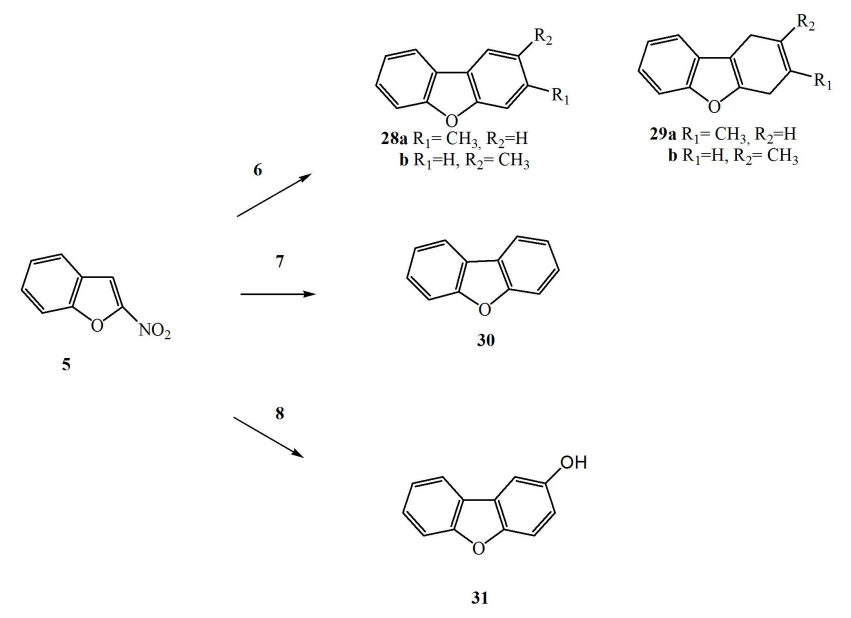

Figure 9. Diels-Alder reactions of 2-nitrobenzofuran with dienes 6, 7 and 8.

\subsection{Azanitronaphathalenes as dienophiles}

It was explored the cycloaddition reactions between 5-nitro and 8-nitroquinolines (32a and 32b)

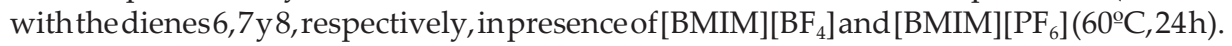<smiles>[R]c1ccc([R])c2ncccc12</smiles>

$$
\begin{aligned}
\text { 32a } \mathrm{R}_{1}=\mathrm{H}, \mathrm{R}_{2}=\mathrm{NO}_{2} \\
\text { b R }_{1}=\mathrm{NO}_{2}, \mathrm{R}_{2}=\mathrm{H}
\end{aligned}
$$

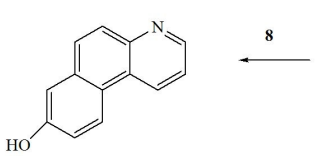

35

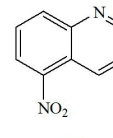

32a

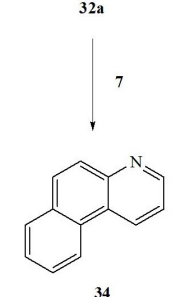

Figure 10. Diels-Alder reactions of 5-nitroquinoline with 6,7 and 8 . 
The reactions of 5-nitroquinoline with these dienes, yield the same products that using [HMIM] $\left[\mathrm{BF}_{4}\right]$ as solvent but with lower yield. In the cases of dienes 7 and 8 the normal addition products 34 and 35, respectively, show complete aromatization due to the loss of the nitro and trimethylsyliloxy groups. The product 35 was obtained with complete regioselectivity. However, when the diene 6 was used the observed cycloaddition products was (9Methyl-7,10-dihydro-benzo [f]quinoline) 33 with traces of its regioisomers (Cancian, et al, 2010) (Figures 10 ) (Tables 9).

\begin{tabular}{|c|c|c|c|c|}
\hline Entry & Dieno $^{a}$ & Conditions $^{b}$ & Products & Yield $(\%)^{c}$ \\
\hline 1 & 6 & EAN & 33 & 18 \\
\hline 2 & & {$[\mathrm{HMIM}]\left[\mathrm{BF}_{4}\right]$} & 33 & 16 \\
\hline 3 & & {$[\mathrm{HMIM}]\left[\mathrm{PF}_{6}\right]$} & 33 & 16 \\
\hline 4 & & {$[\mathrm{BMIM}]\left[\mathrm{BF}_{4}\right]$} & 33 & 12 \\
\hline 5 & & {$[\mathrm{BMIM}]\left[\mathrm{PF}_{6}\right]$} & 33 & 12 \\
\hline 6 & 7 & EAN & 34 & 22 \\
\hline 7 & & {$[\mathrm{HMIM}]\left[\mathrm{BF}_{4}\right]$} & 34 & 20 \\
\hline 8 & & {$[\mathrm{HMIM}]\left[\mathrm{PF}_{6}\right]$} & 34 & 19 \\
\hline 9 & & {$[\mathrm{BMIM}]\left[\mathrm{BF}_{4}\right]$} & 34 & 14 \\
\hline 10 & & {$[\mathrm{BMIM}]\left[\mathrm{PF}_{6}\right]$} & 34 & 14 \\
\hline 11 & 8 & EAN & 35 & 25 \\
\hline 12 & & {$[\mathrm{HMIM}]\left[\mathrm{BF}_{4}\right]$} & 35 & 20 \\
\hline 13 & & {$[\mathrm{HMIM}]\left[\mathrm{PF}_{6}\right]$} & 35 & 20 \\
\hline 14 & & {$[\mathrm{BMIM}]\left[\mathrm{BF}_{4}\right]$} & 35 & 15 \\
\hline 15 & & {$[\mathrm{BMIM}]\left[\mathrm{PF}_{6}\right]$} & 35 & 15 \\
\hline \multicolumn{5}{|c|}{$\begin{array}{l}\text { a Diene/dienophile ratio } 3: 1 \\
\text { b Reaction's time } 24 \mathrm{~h} \text {, reaction's temperature } 60^{\circ} \mathrm{C} \text {. } \\
\text { ' Based on consumed dienophile. }\end{array}$} \\
\hline
\end{tabular}

Table 9. Diels-Alder reactions of dienophile 32a with different dienes.

\begin{tabular}{ccccc}
\hline Entry & Dieno $^{\mathbf{a}}$ & Conditions $^{\mathbf{b}}$ & Products & Yield (\%) $^{\mathbf{c}}$ \\
\hline 1 & $\mathbf{6}$ & $\mathrm{EAN}$ & $\mathbf{3 6}$ & 17 \\
\hline 2 & & {$[\mathrm{HMIM}]\left[\mathrm{BF}_{4}\right]$} & $\mathbf{3 6}$ & 15 \\
\hline 3 & {$[\mathrm{HMIM}]\left[\mathrm{PF}_{6}\right]$} & $\mathbf{3 6}$ & 15 \\
\hline 4 & {$[\mathrm{BMIM}]\left[\mathrm{BF}_{4}\right]$} & $\mathbf{3 6}$ & 12 \\
\hline 5 & & {$[\mathrm{BMIM}]\left[\mathrm{PF}_{6}\right]$} & $\mathbf{3 6}$ & 12 \\
\hline 6 & $\mathbf{7}$ & $\mathrm{EAN}$ & $\mathbf{3 7}$ & 20 \\
\hline 7 & & {$[\mathrm{HMIM}]\left[\mathrm{BF}_{4}\right]$} & $\mathbf{3 7}$ & 18 \\
\hline 8 & & {$[\mathrm{HMIM}]\left[\mathrm{PF}_{6}\right]$} & $\mathbf{3 7}$ & 19 \\
\hline
\end{tabular}




\begin{tabular}{|c|c|c|c|c|}
\hline Entry & Dieno $^{a}$ & Conditions $^{b}$ & Products & Yield (\%) \\
\hline 9 & & {$[\mathrm{BMIM}]\left[\mathrm{BF}_{4}\right]$} & 37 & 13 \\
\hline 10 & & {$[\mathrm{BMIM}]\left[\mathrm{PF}_{6}\right]$} & 37 & 13 \\
\hline 11 & 8 & EAN & 38 & 24 \\
\hline 12 & & {$[\mathrm{HMIM}]\left[\mathrm{BF}_{4}\right]$} & 38 & 20 \\
\hline 13 & & {$[\mathrm{HMIM}]\left[\mathrm{PF}_{6}\right]$} & 38 & 20 \\
\hline 14 & & {$[\mathrm{BMIM}]\left[\mathrm{BF}_{4}\right]$} & 38 & 15 \\
\hline 15 & & {$[\mathrm{BMIM}]\left[\mathrm{PF}_{6}\right]$} & 38 & 15 \\
\hline \multicolumn{5}{|c|}{$\begin{array}{l}\text { a Diene/dienophile ratio } 3: 1 \\
\text { b Reaction's time } 24 \mathrm{~h} \text {, reaction's temperature } 60^{\circ} \mathrm{C} \text {. } \\
\text { ' Based on consumed dienophile. }\end{array}$} \\
\hline
\end{tabular}

Table 10. Diels-Alder reactions of dienophile 32b with different dienes.

In the same way, the reactions of 8-nitroquinoline with these dienes, yield the same products that using $[\mathrm{HMIM}]\left[\mathrm{BF}_{4}\right]$ as solvent but with lower yield. When the were dienes 7 and 8 the normal addition products 37 and 38, respectively, show complete aromatization due to the loss of the nitro and trimethylsyliloxy groups. The product 37 was obtained with complete regioselectivity. However, when the diene 6 was used the observed cycloaddition products was (9-Methyl-7,10-dihydro-benzo[h]quinoline) 36 with traces of its regioisomers (Cancian, et al, 2010) (Figures 11 ) (Tables 10).

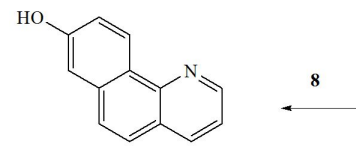

38

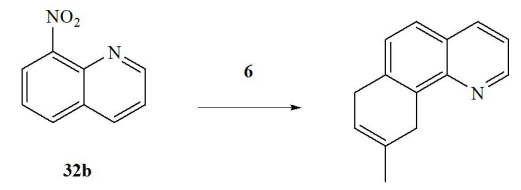

36<smiles>c1ccc2c(c1)ccc1cccnc12</smiles>

37

Figure 11. Diels-Alder reactions of 8-nitroquinoline with 6, 7 and 8.

\subsection{Nitronaphthalenes as dienophiles}

To explore the normal electron-demand D-A dienophilicity of nitronaphtahlenes in presence of no-protic ILs ([BMIM] $\left[\mathrm{BF}_{4}\right]$ and $\left.[\mathrm{BMIM}]\left[\mathrm{PF}_{6}\right]\right)$ we selected 1-nitronaphthalene 39 as electrophile and 8 as diene. 
When 39 and 8 were heated in a sealed ampoule $\left(60^{\circ} \mathrm{C}, 24 \mathrm{~h}\right)$ using [BMIM] $\left[\mathrm{BF}_{4}\right]$ and [BMIM] $\left[\mathrm{PF}_{6}\right]$, respectively, as solvents, in both cases ca de $50 \%$ of 2 -hydroxy-phenanthrene 40 , was regioselectively produced. The regioselectivity of these reactions was controlled by both the nitro group of the dienophile and the methoxyl group of Danishefsky's diene. This product was obtained when a PILs was used (e.g. $\left.[\mathrm{HMIM}]\left[\mathrm{BF}_{4}\right]\right)$, however in this case with major yield The preference for the normal D-A products in the presence of ILs respect the use of molecular solvent, probably is due to the increase of the electrophilicity of the dinenophile (Figure 12).<smiles>O=[N+]([O-])c1cccc2ccccc12</smiles>

39<smiles>C=C(/C=C/OC)OC</smiles>

8<smiles>Oc1ccc2c(ccc3ccccc32)c1</smiles>

40

Figure 12. Diels- Alder reaction of 1-nitronaphthalene with Danishefsky's diene.

\section{Diels-Alder reactions employing ionic liquids and microwave irradiation}

Ionic liquids are becoming promising and useful substitutes for standard organic solvents. Not only they are environmentally benign, they also possess unique chemical and physical properties. Moreover, microwave irradiation has been used to enhance organic reactions in which an ionic liquid is used as the solvent. Ionic liquids absorb microwave irradiation extremely well and transfer energy rapidly by ionic conduction.

The D-A transformations usually require harsh conditions (high temperatures and pressures) and long reaction times. These cycloadditions were the first reaction type to be examined in conjunction with microwave irradiation. Microwave irradiation has also been used to enhance organic reaction in which an ionic liquid is used as the solvent.

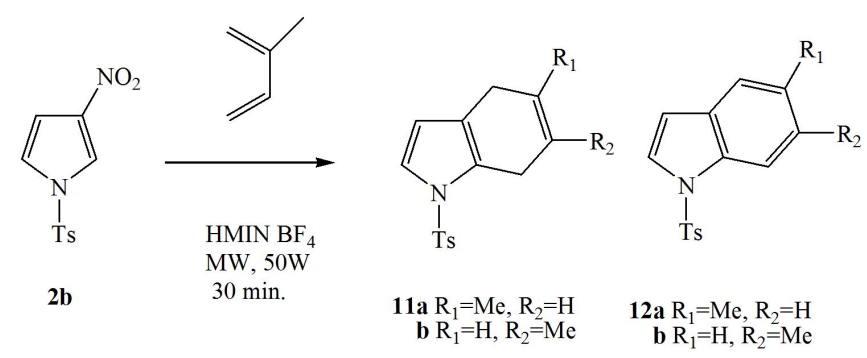

Figure 13. Diels-Alder reaction of 1-tosyl-3-nitropyrrole with isoprene. 
With microwave irradiation (50 W, $30 \mathrm{~min}$.) and [HMIM] $\left[\mathrm{BF}_{4}\right]$ as reaction media, 1-tosyl-3nitropyrrole reacts with isoprene yielding the mixture of isomeric dihydroindoles 11a and $11 \mathrm{~b}$ and indoles $12 \mathrm{a}$ and $12 \mathrm{~b}$ as the principal.products (global yield 95\%). (Figure 13)

In turn, nitrobenzene react with isoprene using benzene as solvent to offer pyrroliybenzene as product in reasonable yield. If the diene is 8 we do not observe reaction probably due to the strong aromatic character of this substrate. It call our attention the absence of reactivity when nitrobenzene reacted with 6 in presence of $[\mathrm{HMIM}]\left[\mathrm{BF}_{4}\right]$ and microwave irradiation. This result would be consequence of the strong interaction between the nitro group and the PIL.

\section{Theoretical studies}

\subsection{General}

The Density Functional Theory (DFT) is a model of quantum mechanics used to obtain electronic structure of different systems, in this case, molecules involved in the Diels-Alder reaction. Considering this theory, there are some parameters (or indexes) that can be used to explain the reactivity and regioselectivity of the cycloaddition reactions. The most significant ones are the chemical hardness $(\eta)$,that describes the resistance of the chemical potential to a change in the number of electrons, and the electronic chemical potential $(\mu)$, which is usually associated with the charge-transfer (CT) ability of the system in its ground state geometry. Both quantities can be approximated in terms of the energies of the HOMO and LUMO frontier molecular orbitals (Eqs. 1 and 2) (Domingo, et al, 2002; Domingo \& Aurell, 2002).

$$
\begin{gathered}
\eta=\left(\varepsilon_{\text {LUMO }}-\varepsilon_{\text {HOMO }}\right) \\
\mu=\frac{\left(\varepsilon_{\text {LUMO }}+\varepsilon_{\text {HOMO }}\right)}{2}
\end{gathered}
$$

Based on these parameters Parr (Parr, et al, 1999) introduced the global electrophilicity in$\operatorname{dex}(\omega)$, an useful descriptor of the reactivity that allows a quantitative classification of the electrophilicity character of the whole molecule in an unique scale. This index is defined as:

$$
\omega=\frac{\mu^{2}}{2 \eta}
$$

Current studies based on the DFT have shown that this classification is a powerful tool to predict and justify the feasibility of the D-A process and the type of mechanism involved. The electrophilicity scale describes the effects of electron-donor and electron-withdrawing groups in the diene/dienofile pair. Reactants can be classified for the D-A cycloaddition as strong $(>1.50 \mathrm{eV})$, moderate $(1.49-0.90 \mathrm{eV})$ and poor $(<0.90 \mathrm{eV})$ electrophiles. 
The difference in electrophilicity between the diene/dienofile pair can be related to the electronic pattern expected in the transition state (TS) of a D-A process and, in consequence, its has been proposed as a measure of the polar character of the reaction.

Additionally, there are local reactivity indexes that are associated with site selectivity in a chemical reaction. They can be calculated from the Fukui function (Parr, R. G. et al 1984). Eq. (4) provides a simple and direct formalism to obtain it from an approach based on a relationship between the FMOs.

$$
f_{k}^{\alpha}=\sum_{\mu \in k}\left|c_{\mu \alpha}\right|^{2}+\sum_{v \neq \mu} c_{\mu \alpha} c_{v \alpha} S_{\mu v}
$$

The condensed Fukui function for electrophilic attacks involves the HOMO FMO coefficients (c) and the atomic overlap matrix elements (S).

In this direction, to analyze at which atomic site of a molecule the maximum electrophilicity value is reached, Domingo (Domingo, et al, 2002) has introduced Eq. (5)

$$
\omega_{k}=\omega f_{k}^{+}
$$

On the other hand, the first approach toward a quantitative description of nucleophilicity has also been reported by Domingo (Domingo, et al, 2008). The global nucleophilicity index, $N$, is defined in Eq. (6)

$$
N=\left(\varepsilon_{H O M O, N u}-\varepsilon_{H O M O, T C E}\right)
$$

Where $\varepsilon_{\text {нОмо,тСE }}$ is the HOMO energy of tetracyanoethylene (TCE) (taken as a reference molecule due to the fact that it exhibits the lowest HOMO energy in a large series of molecules previously considered in D-A cycloadditions).

Its local counterpart, $N_{k}$, -Eq. (7)- has been developed with the purpose of identifying the most nucleophilic site of a molecule. In this case Eq (4) is considered for a nucleophilic attack and involves LUMO FMO coefficients.

$$
N_{k}=N f_{k}^{-}
$$

This nucleophilicity index has been useful to explain the nucleophilic reactivity of some dienes with electrophiles in cycloaddition as well as substitution reactions (Domingo, et al, 2008).

In general, the polarity of the normal electron demand D-A process is studied trough global electrophilicity indexes difference between reactants. And the regioselectivity of the normal electron demand D-A reaction, using the local electrophilicity index for dienophiles (electrophiles in the reaction) and the local nucleophilicity index for dienes (nucleophiles in the reaction). 
In this stage, we show different theoretical studies related to the polar D-A reactions experimentally described, where the dienophiles are aromatic heterocycles or carbocycles. In the same way, the mechanism of these reactions, specially respect to regio-, site- and stereochemistry have been analyzed in detail.

\subsection{Dienes}

Global electronic properties of the dienes experimentally used in the cycloadditions previously described are exposed in Table 11.

\begin{tabular}{lcccc}
\hline \multirow{2}{*}{ Molecule } & \multicolumn{4}{c}{ Global properties } \\
\cline { 2 - 5 } & $\boldsymbol{\mu ( \text { a.u.) }}$ & $\boldsymbol{\eta}($ a.u.) & $\boldsymbol{\omega}(\mathrm{eV})$ & $\boldsymbol{N}(\mathrm{eV})$ \\
\hline Isoprene & -0.1209 & 0.1962 & 1.01 & 2.93 \\
\hline 1-trimethylsilyloxy-1,3-butadiene & -0.0911 & 0.1977 & 0.75 & 3.59 \\
\hline Danishefsky's diene & -0.0945 & 0.1851 & 0.66 & 3.55 \\
\hline
\end{tabular}

Table 11. Dienes.

As the substitution of the dienes with electron-donor groups increases, its global electrophilicity decrease. This indicates that the diene became a better nucleophile for D-A reaction.

The effect of this kind of substitutive groups is also reflected in the difference between local nucleophilicity indexes of the extreme carbon atoms. Considering these values, regioselectivity of D-A reactions is evaluated.
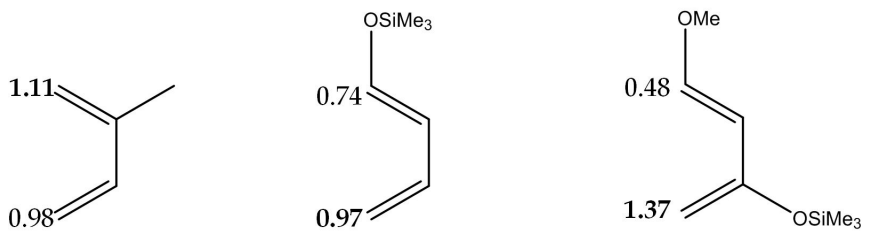

Figure 14. local nucleophilicity index $\left(N_{k}\right)$ in eV.

In Figure 14, local nucleophilicity indexes for carbon atoms that would react in this type of cycloadditions (C1 and C4), are shown. A higher value of nucleophilicity is observed in C4 for 1-trimethylsilyloxy-1,3-butadiene and 1-methoxy-3-trimethylsilyloxy-1,3-butadiene (Danishefsky diene). For isoprene, $\mathrm{C} 1$ is the most nucleophilic atom.

The electrophilicity of isoprene falls in the range of moderate electrophiles within the electrophilicity scale proposed by Domingo et al. When electron-donating substituents, $-\mathrm{OCH}_{3}$ and $-\mathrm{OSi}\left(\mathrm{CH}_{3}\right)_{3}$, are incorporated into the structure of butadiene, a decrease in the electrophilicity power is observed. Therefore, the electrophilicity of Danishefsky's diene falls in the range of marginal electrophiles, good nucleophiles, within the electrophilicity scale. This be- 
havior indicates that the nucleophilic activation in Danishefsky's diene is better than in isoprene, in clear agreement with the high nucleophilicity index of the diene. 1trimethylsilyloxy-1,3-butadiene have a intermediate behavior.

\subsection{Dienophiles}

The electrophilicity power $(\omega)$ of the different dienophiles is shown in Tables $12,13,14,15$, 16 and 17. In the tables we also included some global properties such as the chemical potential and the chemical hardness. A good electrophile is characterized by a high absolute value of $\mu$ and a low value of $\eta$.

We also analyze its local counterpart $\left(\omega_{\mathrm{k}}\right)$, the values are exposed in the Figures 15, 16, 17, 18,19 and 20 below each table.

\subsubsection{Five-membered heterocycles}

- Furan and derivatives.

\begin{tabular}{lcccc}
\hline \multirow{2}{*}{ Molecule } & \multicolumn{4}{c}{ Global properties } \\
\cline { 2 - 5 } & $\boldsymbol{\mu ( \text { a.u.) }}$ & $\boldsymbol{\eta}($ a.u.) & $\boldsymbol{\omega}(\mathrm{eV})$ & $\boldsymbol{N}(\mathrm{eV})$ \\
\hline Furan & -0.1024 & 0.2441 & 0.99 & 3.23 \\
\hline 2-Nitrofuran & -0.1810 & 0.1775 & 2.51 & 1.99 \\
\hline 3-Nitrofuran & -0.1767 & 0.1808 & 2.35 & 2.07 \\
\hline
\end{tabular}

Table 12. global electronic properties.
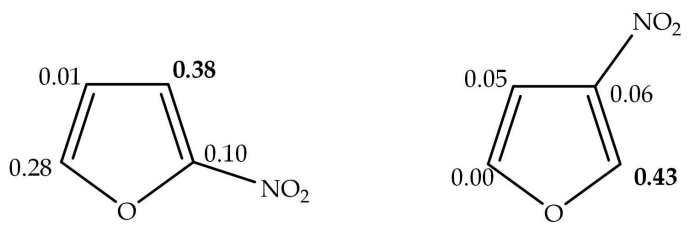

Figure 15. local electrophilicity indexes $\left(\omega_{k}\right)$ in $\mathrm{eV}$.

- Tiophene and derivatives.
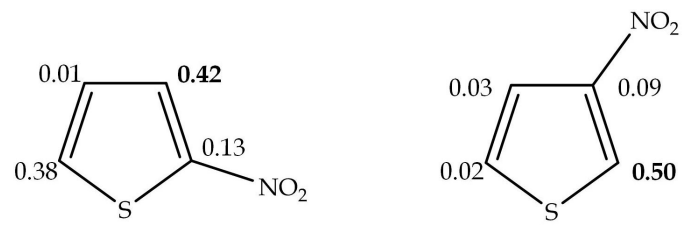

Figure 16. local electrophilicity indexes $\left(\omega_{k}\right)$ in $\mathrm{eV}$. 


\begin{tabular}{lcccc}
\hline \multirow{2}{*}{ Molecule } & \multicolumn{4}{c}{ Global properties } \\
\cline { 2 - 5 } & $\boldsymbol{\mu ( \text { a.u. } )}$ & $\boldsymbol{\eta}($ a.u. $)$ & $\boldsymbol{\omega}(\mathrm{eV})$ & $\boldsymbol{N}(\mathrm{eV})$ \\
\hline Thiophene & -0.1545 & 0.1566 & 0.87 & 3.01 \\
\hline 2-Nitrothiophene & -0.1845 & 0.1738 & 2.66 & 1.95 \\
\hline 3-nitrothiophene & -0.1794 & 0.1821 & 2.40 & 1.98 \\
\hline
\end{tabular}

Table 13. global electronic properties

- Selenophene and derivatives.

\begin{tabular}{lllll}
\hline \multirow{2}{*}{ Molecule } & \multicolumn{4}{c}{ Global properties } \\
\cline { 2 - 5 } & $\boldsymbol{\mu}($ a.u.) & $\boldsymbol{\eta}($ a.u. $)$ & $\boldsymbol{\omega}(\mathrm{eV})$ & $\boldsymbol{N}(\mathrm{eV})$ \\
\hline Selenophene & -0.1220 & 0.2195 & 0.49 & 3.16 \\
\hline 2-Nitroselenophene & -0.1829 & 0.1695 & 2.68 & 2.05 \\
\hline 3-Nitroselenophene & -0.1776 & 0.1803 & 2.38 & 2.05 \\
\hline
\end{tabular}

Table 14. global electronic properties
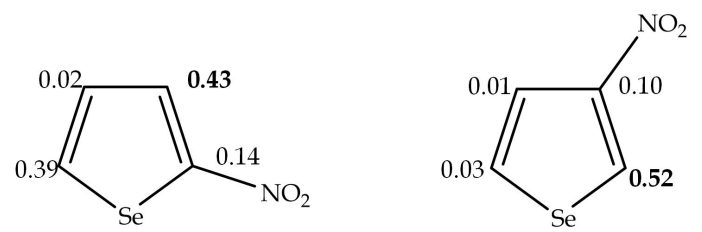

Figure 17. local electrophilicity indexes $\left(\omega_{k}\right)$ in $\mathrm{eV}$.

- 1-Tosyl-pyrrole and derivatives.

\begin{tabular}{lcccc}
\hline \multirow{2}{*}{ Molecule } & \multicolumn{4}{c}{ Global properties } \\
\cline { 2 - 5 } & $\boldsymbol{\mu}$ (a.u.) & $\boldsymbol{\eta}($ a.u. $)$ & $\boldsymbol{\omega}(\mathrm{eV})$ & $\boldsymbol{N}(\mathrm{eV})$ \\
\hline 1-Tosylpyrrole & -0.1348 & 0.1752 & 1.41 & 3.28 \\
\hline 1-Tosyl-2-nitropyrrole & -0.1655 & 0.1739 & 2.31 & 2.43 \\
\hline 1-Tosyl-3-nitropyrrole & -0.1668 & 0.1765 & 2.14 & 2.39 \\
\hline
\end{tabular}

Table 15. global electronic properties. 

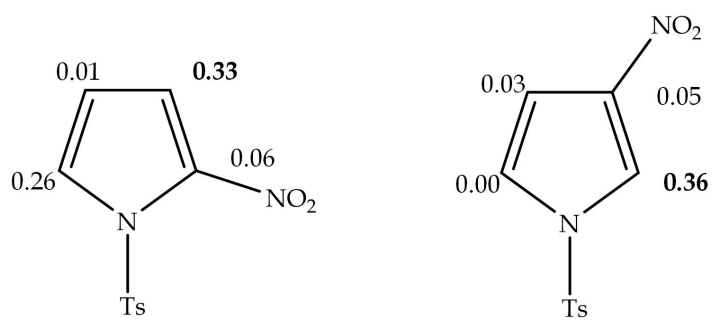

Figure 18. local electrophilicity indexes $\left(\omega_{k}\right)$ in $\mathrm{eV}$.

\subsubsection{Benzofused heterocycles}

- Benzofuran and derivatives.

\begin{tabular}{lcccc}
\hline \multirow{2}{*}{ Molecule } & \multicolumn{4}{c}{ Global properties } \\
\cline { 2 - 5 } & $\boldsymbol{\mu ( \text { a.u.) }}$ & $\boldsymbol{n}($ a.u.) & $\boldsymbol{\omega}(\mathrm{eV})$ & $\boldsymbol{N}(\mathrm{eV})$ \\
\hline Benzofuran & -0.1180 & 0.2032 & 0.93 & 3.36 \\
\hline 2- nitrobenzofuran & -0.1757 & 0.1536 & 2.73 & 2.46 \\
\hline 3-nitrobenzofuran & -0.1694 & 0.1613 & 2.42 & 2.53 \\
\hline
\end{tabular}

Table 16. global electronic properties.
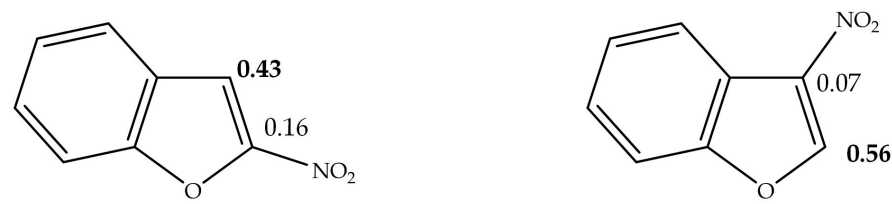

Figure 19. local electrophilicity indexes $\left(\omega_{k}\right)$ in $\mathrm{eV}$.

- N-Tosyl-indole and derivatives.

\begin{tabular}{lcccc}
\hline \multirow{2}{*}{ Molecule } & \multicolumn{4}{c}{ Global properties } \\
\cline { 2 - 5 } & $\boldsymbol{\mu}$ (a.u.) & $\boldsymbol{\eta}$ (a.u.) & $\boldsymbol{\omega}(\mathrm{eV})$ & $\boldsymbol{N}(\mathrm{eV})$ \\
\hline 1-Tosyl-indole & -0.1316 & 0.1683 & 1.40 & 3.47 \\
\hline 1-Tosyl-2-nitroindole & -0.1657 & 0.1455 & 2.57 & 2.84 \\
\hline 1-Tosyl-3-nitroindole & -0.1606 & 0.1562 & 2.25 & 2.84 \\
\hline
\end{tabular}

Table 17. global electronic properties. 

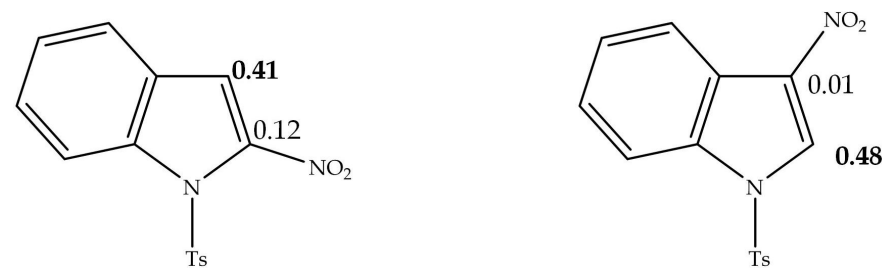

Figure 20. local electrophilicity indexes $\left(\omega_{k}\right)$ in $\mathrm{eV}$.

We can assume that high nucleophilicity and high electrophilicity corresponds to opposite extremes of this scale (Della Rosa, et al, 2011; Brasca, et al, 2009).

The substitution of one hydrogen atom in all the dienophiles by the nitro group, one of the most powerful electron-withdrawing groups, produces an increment in the electrophilicity character and therefore an increase in the reaction rate is expected. The 2-nitro-substituted heterocycles show high electrophilicity power respect to the 3-nitro-substituted ones. Experimentally we obtained higher yields when the nitro group is place in the position 2 of the thiophene's ring than when it is in the 3-position. So these last results support the tendency observed in the tables.

The differences in the global electrophilicity power between the dienophile/diene pair $(\Delta \omega)$ are higher for the Danishefsky's diene than for isoprene. Therefore, we can expect a high reactivity for the pair nitrosubstituted-dienophile/Danishefsky's diene.

As a consequence of the high electrophilic character of these substituted dienophiles and the high nucleophilic character of the dienes, it is expected that these D-A reactions proceed with polar character. The polarity of the process is assessed comparing the electrophilicity index of the interacting pairs. Evidently, the differences in the global electrophilicity power $(\Delta \omega)$ are higher for the Danishefsky's diene than 1-trimethylsilyloxy-1,3-butadiene and isoprene.

On the other hand, a high regioselectivity is expected for Danishefsky's diene, due to the fact that the difference between local nucleophilicity indexes of $C 1$ and $C 4\left(\Delta N_{k}\right)$ presents the highest value in this diene $\left(\Delta N_{k}=0.89\right)$. For isoprene and 1-trimethylsilyloxy-1,3-butadiene, as this difference is low $\left(\Delta N_{k}=0.13\right.$ and $\Delta N_{k}=0.23$ respectively), both isomers are expected as D-A products. For dienophiles, the carbon atom adjacent to the nitro-substituted one is the most electrophile site in all the cases $\left(\Delta \omega_{k=} 0.49-0.27\right)$.

When asymmetric reactants participate in this polar D-A cycloaddition, the most favorable interaction will take place between the most nucleophile site of the diene and the most electrophile site of the dienophile. This fact is also consistent with the experimental researches in ionic liquids as solvents.

When 2-nitrobenzofuran and 3-nitrobenzofuran reacted with isoprene, 1-trimethylsilyloxy-1,3-butadiene and the Danishesfky's diene, under different reaction conditions they showed their dienophilic character taking part in a normal demand polar D-A cycloaddition reactions. 
Finally, the flux of the electron-density in these polar cycloaddition reactions is also supported by means of a DFT analysis besed on the electronic chemical potentials of the reagents. The electronic chemical potentials of the substituted heterocyclic dienophiles, nearly $-5 \mathrm{eV}$, are higher than those of the dienes, nearly $-3 \mathrm{eV}$, thereby suggesting that the net charge transfer will take place from these electron-rich dienes towards the aromatic dienophiles.

According to the global electrophilicity index $\omega$ showed that the dienes will act as nucleophiles and the dienophiles as electrophiles. To study the regioselectivity we used the local electrophilicity and nucleophilicity indexes for dienophiles and dienes respectively. The more favored adducts are the ones where the most electrophilic and nucleophilic sites interact first. In the reactions in which it is possible discussed the regioselectivity of the experimental data agree with the computational results. (Della Rosa, el al, 2011)

The 2-nitrosubstituted benzofuran show higher electrophilicity power than the 3-nitrosubstituted benzofuran probably due to the proximity of the nitro group with the heteroatom.

\subsection{Ionic Liquids effect}

The influence of ILs has also been considered in this theoretical study. For the calculation of electronic properties of the "complexes" dienophile-IL we use a model that includes the dienophile molecule interacting with the anion-cation IL's system. In Table 18 we show an example of the different global electronic properties ( $\omega$ and $N$ ) for these five-membered heterocycle-IL systems in comparison with the same study in gas phase.

\begin{tabular}{|c|c|c|c|c|c|c|}
\hline & \multicolumn{2}{|c|}{$\omega(\mathrm{eV}) \quad N(\mathrm{eV})$} & \multicolumn{4}{|c|}{$\omega(\mathrm{eV}) N(\mathrm{eV})$} \\
\hline \multirow{5}{*}{ 2-nitrofuran } & 2.51 & 1.78 Gas Phase & \multirow{5}{*}{ 3-nitrofuran } & 2.35 & 1.85 & Gas Phase \\
\hline & 4.31 & $1.83[\mathrm{HMIM}][\mathrm{BF} 4]$ & & 4.02 & 2.00 & {$[\mathrm{HMIM}][\mathrm{BF} 4]$} \\
\hline & 4,18 & 1.26 [HMIM][PF6] & & 3.87 & 1.34 & [HMIM][PF6] \\
\hline & 3.02 & 1.52 [BMIM][BF4] & & 2.78 & 1.64 & [BMIM][BF4] \\
\hline & 2.95 & 1.60 [BMIM][PF6] & & 2.63 & 1.49 & [BMIM][PF6] \\
\hline
\end{tabular}

Table 18. Global electronic properties for 2- and 3- nitrofuranes.

It can be observed that for nitrofuran dienophiles the electrophilicity index reach higher values in presence of IL ([HMIM] $\left.\left[\mathrm{BF}_{4}\right],[\mathrm{HMIM}]\left[\mathrm{PF}_{6}\right],[\mathrm{BMIM}]\left[\mathrm{BF}_{4}\right],[\mathrm{BMIM}]\left[\mathrm{PF}_{6}\right]\right)$. The strongest hydrogen-bond donation ability of [HMIM] cation is reflected in the significant increment of $\omega$ in about $2 \mathrm{eV}$ for all the heterocycles in study. The $\left[\mathrm{PF}_{6}\right]^{-}$anion present little lower values than $\left[\mathrm{BF}_{4}\right]^{-}$.

Taking into account that the reactivity of a D-A reaction depends on the HOMO-LUMO energy separation of the reactants, and that in a normal electron demand D-A reaction the strongest interaction takes place between the HOMO of the diene and the LUMO of the dienophile, we compared the corresponding energies of the reacting partners in order to explain the experimental tendency observed. 


\begin{tabular}{cc}
\hline & HOMO (a.u.) \\
\hline Isoprene & -0.2272 \\
\hline 1-trimethylsilyloxy-1,3-butadiene & -0.2046 \\
\hline Danishefsky's diene & -0.2045 \\
\hline
\end{tabular}

Table 19. HOMO energy values.

\begin{tabular}{|c|c|}
\hline & LUMO (a.u.) \\
\hline 2-nitrofuran & -0.0922 \\
\hline 2-nitrofuran+[HMIM] $\left[\mathrm{BF}_{4}\right]$ & -0.1379 \\
\hline 2-nitrofuran+[HMIM] $\left[\mathrm{PF}_{6}\right]$ & -0.1358 \\
\hline 2-nitrofuran+[BMIM] $\left[\mathrm{BF}_{4}\right]$ & -0.1016 \\
\hline 2-nitrofuran+[BMIM] $\left[\mathrm{PF}_{6}\right]$ & -0.1004 \\
\hline
\end{tabular}

Table 20. LUMO energy values.

When the FMO of the reacting pairs are closer in energies, the interaction is higher. Thus, the FMO energies of the reactants were evaluated.

Therefore, in Tables 8 and 9 it can be observed that the expected higher reactivities for the dienophile-IL complexes is due to the fact that LUMO's energy of the dienophile gets closer to the HOMO's energy of the diene, which is consistent with the experimental results. This effect is also revealed by an increase in the yield of the D-A reaction. The energy difference between the FMOs is lower for [HMIM] based IL, what we attribute to the formation of the hydrogen-bond between the nitro group and the IL cation. The tendency is the same in all the cases of nitroheterocycle compounds.

\subsection{Theoretical Mechanistic Approach}

These D-A reactions could be considered domino processes that are initialized by a polar cycloadittion, and the latter concerted elimination of nitrous acid from the [4+2] cycloadduct yields the corresponding products (Della Rosa, et al, 2011).

\subsubsection{Monocyclic five membered nitroheteroaromatic compounds as dienophiles.}

Specifically the reactions of nitro-substituted five-membered heterocycles with Danishefsky 's diene were studied using the hardness, the polarizability and the electrophilicity of the corresponding D-A primary adducts as global reactivity indexes. The experimentally observed products for these D-A reactions using different conditions were indicated in the Figure 21 and related experiments. It has been demonstrated that both the hardness as well as the electrophilicity power of the adducts are appropriate descriptors to predict the major product of the reactions at least in the cases in study. (Brasca, et al, 2011) 


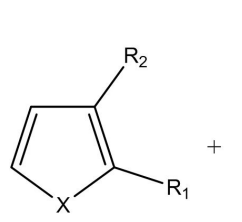
a. $\mathrm{R}_{1}=\mathrm{NO}_{2}, \mathrm{R}_{2}=\mathrm{H}$
b. $\mathrm{R}_{1}=\mathrm{H}, \mathrm{R}_{2}=\mathrm{NO}_{2}$
$\mathrm{X}=\mathrm{O}, \mathrm{S}, \mathrm{Se}, \mathrm{N}-\mathrm{Ts}$
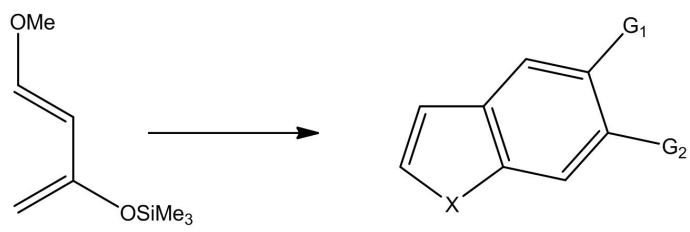

a. $\mathrm{G}_{1}=\mathrm{OH}, \mathrm{G}_{2}=\mathrm{H}$
b. $\mathrm{G}_{1}=\mathrm{H}, \mathrm{G}_{2}=\mathrm{OH}$
$\mathrm{X}=\mathrm{O}, \mathrm{S}, \mathrm{Se}, \mathrm{N}-\mathrm{Ts}$

Figure 21. Reactions of nitrofuran whit Danishefsky diene.

For each reaction four channels, which lead to the regioisomers I, I', II and II' are feasible (Figure 9). As we can observe, depending on the orientation of the nitro group, two stereoisomers can be obtained in each channel (i.e. endo and exo adducts).

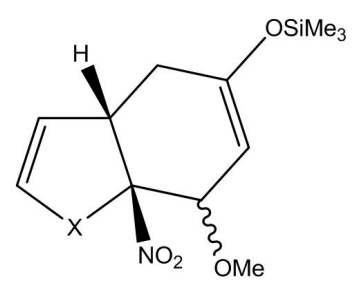

I

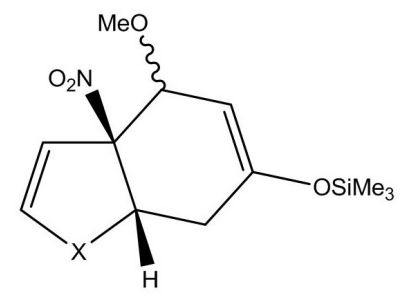

II

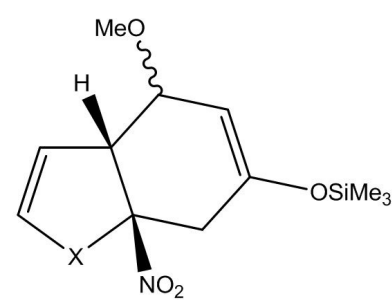

$\mathbf{I}^{\prime}$

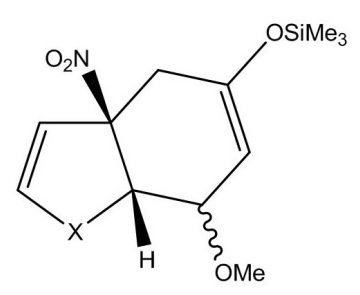

II'

$\mathrm{X}=\mathrm{O}, \mathrm{S}, \mathrm{Se}, \mathrm{N}-\mathrm{Ts}$

Figure 22. Possible regioisomeric D-A adducts.

The regioisomer that have the higher value of $\eta$ and the lower values of $\alpha$ and $\omega$, should correspond to the major product. The calculated hardness and electrophilicity power correctly predict the regioisomers I.a-I.c as the main adducts of the D-A reactions. 
The results obtained in gas phase revealed the same tendency as in ionic liquids as solvents.

We can conclude that the predominant regioisomeric adduct of the reactions between fivemembered heterocycles derivatives and Danishefsky's diene have always the less electrophilicity and high hardness values. Moreover, the regioselectivity experimentally observed can be confirmed by this approach.

The obtained energies show that the I.endo isomer is more stable than the I.exo one. Moreover, the more stable I.endo isomer has lower electrophilicity value than the I.exo isomer in all cases.

The investigation by DFT theory, in which we include solvent effects (considering cation and anion of the ionic liquids), show that these cycloadditions proceeded by a concerted but asynchronus reaction mechanism. The lowest activation energies for concerted reactions are obtained. However, the stepwise additions have significantly lower activation energy lead to substantially less stable products. Moreover, the primary cycloadducts could never be isolated but were converted into 5-hydroxybenzofused heterocycles by subsequent extrusion of nitrous acid, hydrolysis of the silyl enol ether, and elimination of methanol. Elimination of nitrous acid is calculated to have lower overall barriers than cycloaddition reactions and is strongly exothermic, thus explaining the preferred reaction channel.

\subsubsection{Nitronaphthalenes as dienophiles}

The reactions of 1-nitronaphthalene with a serie of dienes were evaluated with the the frontier molecular orbitals (FMO) theory which provide qualitative information about the feasibility of this D-A reaction. Besides, the global electrophilicity index $(\omega)$ is employed to estimate the electrophilic character of the dienophiles used in the cycloaddition reactions.

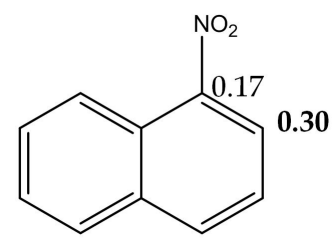

\begin{tabular}{cc}
\hline \multicolumn{2}{c}{ 1-nitronaphtalene } \\
\hline$\mu$ (a.u.) & -0.1650 \\
\hline$\eta(a . u)$ & 0.1485 \\
\hline$\omega(\mathrm{eV})$ & 2.49 \\
\hline $\mathrm{N}(\mathrm{eV})$ & 2.83 \\
\hline
\end{tabular}

Table 21. 1-nitronaphthalene with the Danishefsky diene. 
The reaction of 1-nitronaphthalene with the Danishefsky diene to obtain 3-hydroxyfenantrene has been theoretically studied using DFT methods. This reaction is a domino process that is initialized by a polar Diels-Alder reaction between the par dienophile/diene to give the formally $[2+4]$ cycloadduct. The subsequent concerted elimination of nitrous acid from the primary adduct yields the precursor of the fenatrene derivative. An analysis of the global reactivity indices as well as the thermodynamic data for this domino process indicate that while the large electrophilic carácter of 1-nitronaphthalene together with the large nucleophilic character of Danishefsky diene are responsible for the participation of these reagents in a polar D-A reaction. The D-A reaction has a two-step non-intermediate mechanism characterized by the nucleophilic attack of the non-substituted methylene of the diene to the electrophilically activated C2 position of 1-nitronaphtalene. The subsequentring-closure affords the primary cycloadduct. The latter concerted elimination of nitrous acid yielded the precursor of the tricyclic aromatic final product. Spite of the large activation free energy associated with the D-A reaction and the endergonic character in the primary adduct, the irreversible extrusion of nitrous acid make feasible thermodynamically the domino reaction. (Domingo, et al, 2008)

\subsubsection{Nitroquinolines}

Although the global electrophilicity for the 5-nitroquinoline indicated a lightly major reactivity than the 8-nitro isomer (Figure 23). This result does not agree with the experimental data. In this respect it is possible think that the attack of the dienophile to the para position would be a reversible process, meanwhile the attack to the orto position to the nitro group evolve in form irreversible to the cycloaddition product. The major reactivity of the 8-nitro derivative could be occur due to the presence of electroelectronic factors more favourables which are produced during the nucleophilic attack of the diene, for instance a better stabilization of the negative charge in the nitro group. These effects are not considered in the reagents. (Cancian, et al, 2010)<smiles>O=[N+]([O-])c1cccc2ncccc12</smiles>

$\omega=2.76$<smiles>O=[N+]([O-])c1cccc2cccnc12</smiles>

$\omega=2.34$

Figure 23. Global and local electrophilic indexes for 5- and 8-nitroquinolines.

Analysis of the local electrophilicities $\omega_{\mathrm{k}}$ at 5-nitroquinoleine indicates that the C8 carbon, $\omega_{\mathrm{C} 8}=0.40 \mathrm{eV}$, and the $\mathrm{C} 6$ carbon, $\omega_{\mathrm{C} 6}=0.34 \mathrm{eV}$, are the electrophilic centres of the quinoleine moiety, while at 8-nitroquinoleine these centers are the $\mathrm{C} 5$ carbon, $\omega_{\mathrm{C} 5}=0.37 \mathrm{eV}$, 
and the C7 carbon. They correspond with the carbon that contains the nitro group and that located at the ortho position.

Formation of the $\mathrm{HB}$ between the acidic N10 hydrogen of $\mathrm{HMIM}^{+}$and the $\mathrm{O} 9$ oxygen of the nitro group does not only increase the electrophilicity index of the nitroquinoleine-PIL complexes, but also polarizes nitroquinoleine system. At the nitroquinoleine-PIL complexes, the most electrophilic centres are the $\mathrm{C} 8$ carbon, $\omega_{\mathrm{C} 5}=0.55 \mathrm{eV}$, and the $\mathrm{C} 6$ carbon, $\omega_{\mathrm{C} 7}=0.54 \mathrm{eV}$, at 5nitroquinoleine-PIL, and at the $\mathrm{C} 5$ carbon, $\omega_{\mathrm{C} 5}=0.45 \mathrm{eV}$, and the $\mathrm{C} 7$ carbon, $\omega_{\mathrm{C} 7}=0.40 \mathrm{eV}$, at 8nitroquinoleina-PIL. These results are similar to those found in 5- and 8-nitroquinoleines.

Using the 5 and 8-nitroquinoline we showed specifically the interactions models with the lowest energy between the dienophile and [HMIM][BF4] acting as reaction media.

Isoprene vs. 5-nitroquinoleine and 8-nitroquinoleine. A theoretical mechanism study.

In order to understand the catalytic role of polar ionic liquids (PILs) in P-DA reactions between isoprene and nitroquinoleines, in the absence and in the presence of [HMIM][BF4] as a model of PILs, were theoretically studied using DFT methods. These reactions are domino processes that comprises two consecutive reactions:

1. a P-DA reaction between isoprene, acting as diene, and nitroquinoleines acting as dienophiles, to yield the formal [4+2] cycloadducts (CA) and;

2. a concomitant nitroso acid extrusion at these intermediates to yield the final products (Figure 24).

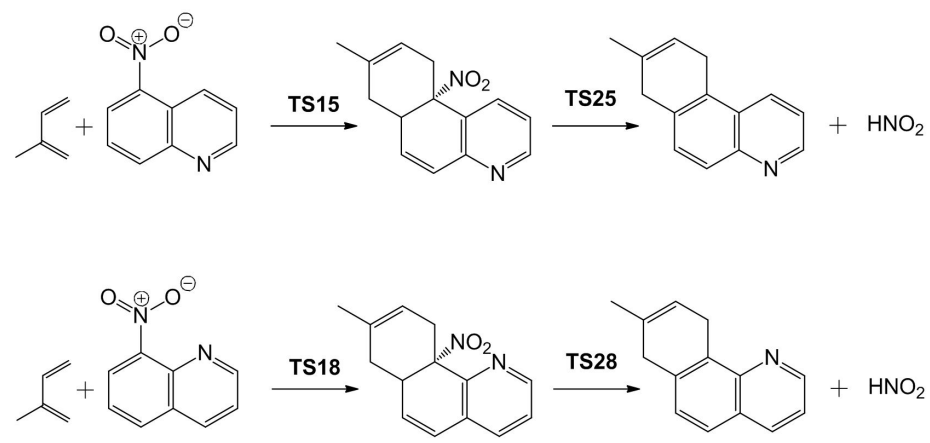

Figure 24. Reaction of isoprene with 5- and 8-nitroisoquinoline

Four reactive channels for the initial attack of isoprene on these nitroquinoleines are feasible: two pairs of stereoisomeric channels, the endo and the exo ones, and two pairs of regioisomeric channels, the meta and the para ones. Since both endo and exo channels yield the same final products after extrusion of nitroso acid, and as P-DA reactions involving isoprene present low regioselectivity, only the channels associated with the endo/para approach mode of isoprene, respect to the electron-withdrawing nitro group of nitroquinoleines were considered. 
An analysis of the gas-phase potential energy surfaces (PES) associated with these P-DA reactions indicates that the cycloadditions take place through a one-step mechanism via high asynchronous transition states (TS). Therefore, in both cases one TS, TS15 and TS18, and the formal [4+2] CAs, were located and characterized. The second reaction of these domino processes also takes place via a one-step mechanism via a high asynchronous TSs. Thus, one TS, TS25 and TS28, and the corresponding final products were located and characterized. Total and relative gas-phase energies are given in Table 11.

\begin{tabular}{ccc}
\hline & $\mathbf{E}$ & $\boldsymbol{\Delta E}$ \\
\hline Isoprene & -195.3055 & \\
\hline 5-nitroquinoleine & -606.4260 & \\
Cycloadduct & -801.6914 & 25.2 \\
TS25 & -801.7496 & -11.4 \\
Product & -801.7129 & 11.6 \\
HNO 2 & -205.6952 & \\
\hline Product + HNO ${ }_{2}$ & -801.7727 & -25.9 \\
\hline 8-nitroquinoleine & -606.4195 & \\
TS18 & -801.6819 & 27.0 \\
Cycloadduct & -801.7499 & -15.6 \\
\hline TS28 & -801.7136 & 7.2 \\
Product & -596.0798 & \\
Product + HNO & -801.7750 & -31.4 \\
\hline
\end{tabular}

Table 22. Gas phase total energies $(E$, in au) and relative energies $(\Delta E$, in $\mathrm{kcal} / \mathrm{mol})$ of the stationary points involved in the domino reaction between isoprene and nitroquinoleines (5- and 8- nitrosubstituted).

In gas phase, the activation energies associated with the nucleophilic attack of the $\mathrm{C} 1$ carbon of isoprene on the C6 carbon of nitroquinoleines via TS15 or TS18 present high values, 25.2 and $27.0 \mathrm{kcal} / \mathrm{mol}$; formation of the formal [4+2] CAs are exothermic by -11.4 and $-15.6 \mathrm{kcal} /$ mol, respectively. Although these P-DA reactions are thermodynamically favorable, these high activation energies associated with these processes prevent the cycloaddition reactions.

The [4+2] CAs suffer a nitroso acid extrusion regenerating the aromatic system present in quinoleine. The activation energies associated with the nitroso acid extrusion via TS25 and TS28 are 23.0 and $28.8 \mathrm{kcal} / \mathrm{mol}$; formation of the tricyclic compounds plus nitroso acid is exothermic by -14.5 and $-15.8 \mathrm{kcal} / \mathrm{mol}$, respectively. Taking into account the favorable reaction entropies associated with the extrusion processes, we can consider these reactions thermodynamically irreversible. Since TS25 and TS28 are located below TS15 and TS18, the P-DA reactions between isoprene 1 and nitroquinoleines 2 or 3 via TS15 and 
TS18 become the rate-determining steps of these domino processes. The high activation energy associated with TS15 and TS18 are in agreement with the drastic reaction conditions demanded for the reactions to take place.

These activation energies are higher than those associated with the P-DA reaction and nitroso acid extrusion associated with the domino reaction between nitronaphtalene and Danishefsky's diene, 16.5 and $23.9 \mathrm{kcal} / \mathrm{mol}$, respectively (Figure 25).
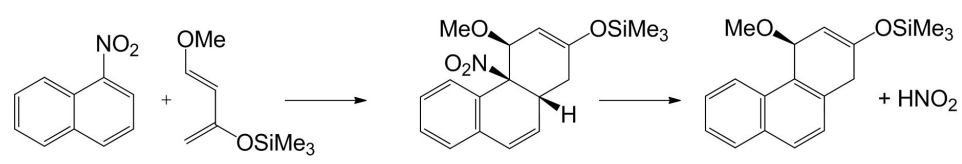

Figure 25. 1-nitronaphtalene and Danishefsky's diene

However, the lower activation energy associated with the P-DA reaction between nitronaphtalene and Danishefsky's diene, and the endothermic character of the formation of the formal [4+2] CA turn the nitroso acid extrusion into the rate-determining step in this domino reaction.
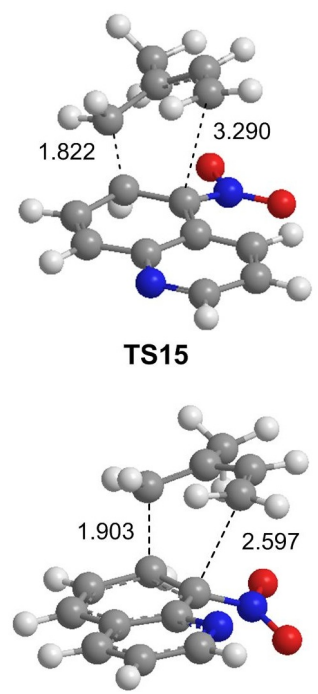

TS18
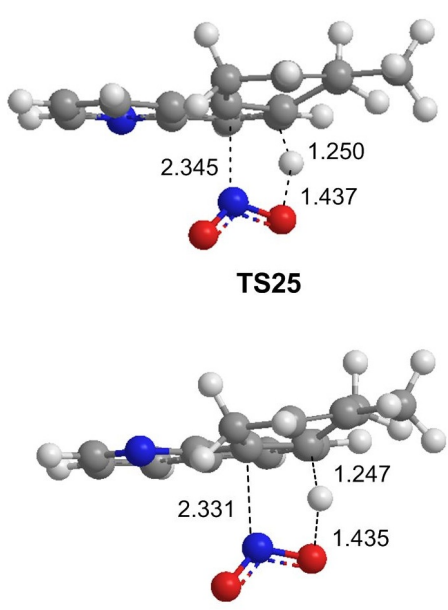

TS28

Figure 26. TS of the reaction between 5- and 8-nitroquinoline and isoprene

The gas-phase geometries of TS15, TS18, TS25 and TS28 are given in Figure 13. The lengths of the $\mathrm{C} 1-\mathrm{C} 5$ and $\mathrm{C} 2-\mathrm{C} 8$ forming bond at TSs associated with the P-DA reactions between 
isoprene and nitroquinoleines are 1.822 and $3.290 \AA$ at TS15 and 1.903 and $2.597 \AA$ at TS18, respectively. These values suggest asynchronous bond-formation processes in which the C$\mathrm{C}$ bond formation between the most nucleophilic center of isoprene, the $\mathrm{C} 5$ carbon, and one of the most electrophilic centers of nitroquinoleines, the $\mathrm{C} 1$ carbon, is more advanced than the $\mathrm{C}-\mathrm{C}$ bond formation between the $\mathrm{C} 2$ and $\mathrm{C} 8$ carbons. The short $\mathrm{C} 1-\mathrm{C} 5$ distance indicates that the cycloaddition processes are very advanced, in clear agreement with the high activation energies associated with TS15 and TS18.

At TSs associated with the nitroso acid extrusion the length of the C2-N3 breaking bond is $2.345 \AA$ at TS25 and $2.331 \AA$ at TS28, while the lengths of the C1-H1 breaking- and O4-H1' forming-bonds are 1.250 and $1.437 \AA$ at TS25, and 1.247 and $1.435 \AA$ at TS28, respectively. These values suggest asynchronous processes in which the C2-N3 breaking bond is more advanced than the $\mathrm{H} 1$ ' proton transfer process to the $\mathrm{O} 4$ oxygen.

The polar nature of these D-A reactions was evaluated analyzing the charge transfer (CT) at TS15 and TS18. The natural charges at these TSs were shared between the isoprene and the nitroquinoleine frameworks. At TS15 and TS18, the CT that flows from isoprene to nitroquinoleines is $0.29 \mathrm{eV}$ and $0.26 \mathrm{eV}$, respectively. These values point at the zwitterionic character of these TSs. They are lower than that obtained at the TS associated with the nucleophilic attack of Danishefsky's diene on nitronaphtalene, $0.39 \mathrm{eV}$, as a consequence of the stronger nucleophilic character of Danishefsky's diene than that of isoprene.

Reaction mechanism pattern in presecence of the [HMIM][BF4] PIL.

The effects of the $[\mathrm{HMIM}]\left[\mathrm{BF}_{4}\right]$ PIL on the domino reactions between isoprene and nitroquinoleines were evaluated considering two computational models. In Model I, the implicit effects of the PIL were considered by forming a hydrogen bond $(\mathrm{BH})$ between the acidic H10 hydrogen of HMIM and the O9 oxygen of the nitro group of nitroquinoleines (Figure 27).

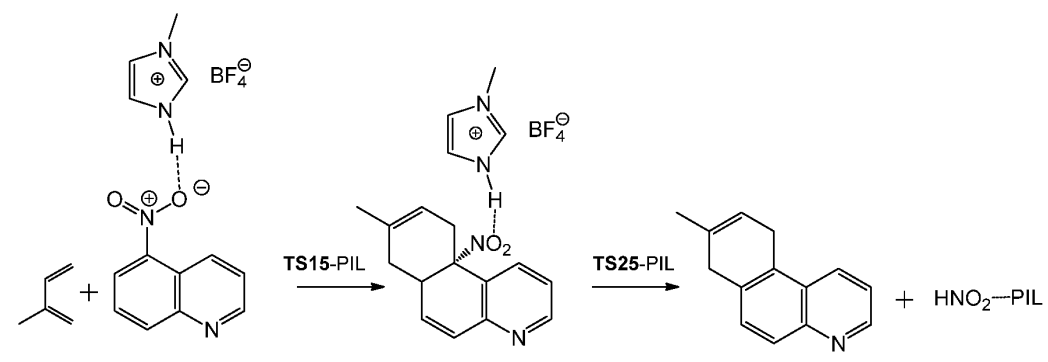

Figure 27. Reaction between 5-nitroquinoline and isoprene in presence of PIL's

While in Model II, the solvent effect of the PIL is completed including electrostatic interactions modeled by the polarizable continuum model (PCM) of Tomasi's group. For the PCM calculations, 1-heptanol was considered as solvent since it has a dielectric constant closer to [HMIM][BF4]; $\varepsilon=11.3$. The energy results are given in Table 12. 


\begin{tabular}{ccccc}
\hline & gas phase & \multicolumn{3}{c}{ 1-heptanol } \\
\hline & $\mathbf{E}$ & $\boldsymbol{\Delta E}$ & $\mathbf{E}$ & $\boldsymbol{\Delta} \mathbf{E}$ \\
\hline 5-nitroquinoleine-PIL & -1297.0092 & & -1297.0411 & \\
TS15-PIL & -1492.2827 & 20.1 & -1492.3173 & 19.4 \\
cycloadduct-PIL & -1492.3293 & -9.2 & -1492.3636 & -9.7 \\
TS25-PIL & -1492.3020 & 8.0 & -1492.3395 & 5.5 \\
HNO 2 -PIL & -896.2688 & & -896.30298 & \\
Product + HNO 2 -PIL & -1492.3463 & -19.8 & -1492.3857 & -23.5 \\
\hline 8-nitroquinoleine-PIL & -1297.0040 & & -1297.0391 & \\
TS18-PIL & -1492.2736 & 22.5 & -1492.3117 & 21.6 \\
cycloadduct-PIL & -1492.3341 & -15.4 & -1492.3673 & -13.3 \\
TS2-PIL & -1492.3021 & 4.6 & -1492.3397 & 4.1 \\
Product + HNO ${ }_{2}$-PIL & -1492.3486 & -24.5 & 1492.3873 & -25.8 \\
\hline
\end{tabular}

Table 23. Total energies ( $E$, in au) and relative energies $(\Delta E$, in $\mathrm{kcal} / \mathrm{mol})$, in gas phase and in 1-heptanol, of the stationary points involved in the domino reaction between isoprene and nitroquinoleines in [HMIM][BF4].

In Figure 27, the stationary points involved in the domino reactions between isoprene and $[\mathrm{HMIM}]\left[\mathrm{BF}_{4}\right]$ :nitroquinoleines complexes are given. Formation of the HB between HMIM and an oxygen atom of the nitro group decreases the activation energies associated with these P-DA reactions significantly. Now, TS1-PIL and TS2-PIL are located 20.1 and 22.5 $\mathrm{kcal} / \mathrm{mol}$ above the separated reagents. In spite of this behaviour, the exothermic character of the cycloadditions, -9.2 and $-15.4 \mathrm{kcal} / \mathrm{mol}$, remains unmodified. The large acceleration found in the presence of the PIL ionic pair can be understand as an increase of the polar character of the reactions as a consequence of the increased electrophilic character of the dienophile-PIL complexes, which favors the CT process.

The second reactions of these domino processes are also slightly catalyzed by the presence of $[\mathrm{HMIM}]\left[\mathrm{BF}_{4}\right] \mathrm{PIL}$, since it remains hydrogen-bonded at the intermediate cycloadductsPIL. Now, the activation energies associated with the extrusion of $\mathrm{HNO}_{2}$-PIL are 17.2 and $20.0 \mathrm{kcal} / \mathrm{mol}$. These reactions are exothermic by -10.6 and $-9.1 \mathrm{kcal} / \mathrm{mol}$.

Inclusion of the solvent effects by means of the PCM calculations in Model II stabilizes all species between 21.0 and $25.0 \mathrm{kcal} / \mathrm{mol}$, as a consequence of the charged [HMIM] [BF ${ }_{4}$ ] PIL. TS15 and TS18 are slightly more stabilized than the reagents due to their zwitterionic character. As a consequence, the activation energies associated with the P-DA reactions decrease by 1.7 and $0.9 \mathrm{kcal} / \mathrm{mol}$ relative to the gas-phase calculations. Consequently, a comparison between the gas-phase relative energies associated with the domino reactions between isoprene and nitroquinoleines with those obtained in Model I and II for the domino reactions in PILs indicate that the HB formation at nitroquinoleines 2 and 3 is the main factor responsible for the acceleration of these domino reactions in PILs. 
The gas-phase geometries of TS15-PIL, TS18-PIL, TS25-PIL and TS28-PIL are given in Figure 15. The lengths of the C1-C5 and C2-C8 forming bonds at the TSs associated with the P-DA reactions between isoprene and the dienophile-PIL complexes are 1.879 and $3.338 \AA$, and 1.835 and $3.141 \AA$, respectively. These values suggest a two-stage one-step mechanism channel an asynchronous TS. At TS15-PIL and TS18-PIL, the distances between the nitro O9 oxygen and the acidic H10 hydrogen of HMIM, 1.769 and $1.776 \AA$, suggest a strong HB interaction.

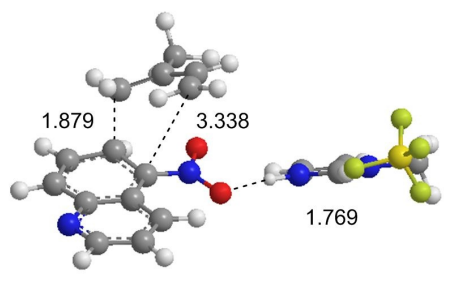

TS15-PIL

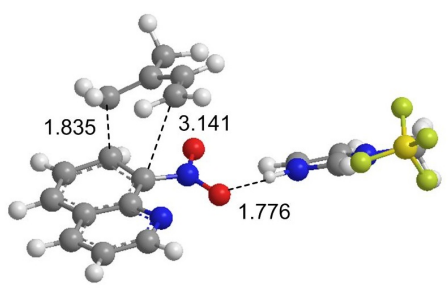

TS18-PIL

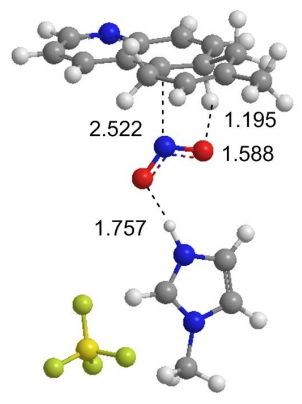

TS25-PIL

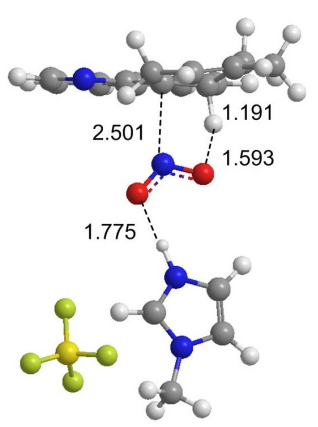

TS28-PIL

Figure 28. TS of the reaction between 5-nitroquinoline and isoprene in presence of PIL's

At TSs associated with the extrusion of the 6-PIL complex, the length of the C2-N3 breaking bond is $2.522 \AA$ at TS25-PIL and 2.501 $\AA$ at TS28-PIL, while the lengths of the C1-H1' breaking- and O4-H1' forming-bonds are 1.195 and $1.588 \AA$ at TS25-PIL, and 1.191 and $1.593 \AA$ at TS28-PIL, respectively. These values also suggest a highly asynchronous process in which the C2-N3 breaking bond is very advanced with respect to the H1' proton transfer process.

\section{Conclusions}

It was possible to demonstrate again the influence of the solvent in these particular type of D-A reactions. A series of aromatic carbocyclic and hetrocyclic substituted by electron with- 
drawing groups can act as dienophiles in polar cycloaddition reactions besides different dienes in the presence of PIL's. However, D-A reactions proceed at an appreciable rate only when either the diene or the dienophile are activated by an electron donating or electron withdrawing group, normally characterized by the presence of a heteroatom that can therefore efficiently interact with the solvent. IL's, with their peculiar properties such as high polarizability/dipolarity, good hydrogen bond donor ability, were straight away considered to have the potential to influence the outcome of these D-A reactions, accelerating them.

In general, the products of the reactions development in PIL's are similar to those in molecular solvents. However, the presence of PIL's improved the reaction rate probably due to the hydrogen bonding interactions between the neoteric solvent and the dienophile. Only in a few cases we can note differences in the product distribution. For the reactions in which are possible to observe a competition between normal and hetero D-A process, the PIL's favor the normal pathway because they improve the electrophilicity of the dienophiles.

The DFT analysis of the global properties of the interacting pair diene/dienophile illustrates the normal electron demand character of these D-A reactions. It is possible to show that the local indexes provide useful clues about the regiodirector effects, particularly of the nitro group. The presence of a solvent (molecular or neoteric) as the reaction media does not impart a prominent influence on the relative reactive sites. In few cases among those studied we can note that the relative reactive sites are affected by the solvent and the basis set (e.g. methyl 5-nitrofuran-2-carboxylate).

The site-, regio-, and stereochemistry of some of these D-A reactions has been investigated by the density functional theory, including solvent effects. Generally, these cycloadditions proceed by a concerted but asynchronous reaction mechanism. The endo stereochemistry is in most case preferred.

In general, the normal D-A reaction mechanism is a domino process that is initialized by the polar reaction between the diene and the dienophile to give the primary cicloadduct. These D-A reactions have a two-step non-intermediate mechanism characterized by the nucleophilic attack on the non-substituted methylene of the diene to the electrophilically activated position of the dienophile. The subsequent ring-closure affords the primary cicloadduct. This behavior makes the reaction to be regioselective. The latter concerted elimination of the nitrous acid from the primary cicloadduct yields the precursor of the final aromatic product. Spite of the large activation free energy associated with the D-A reaction and the endergonic character of formation of the primary cicloadduct, the irreversible extrusion of the nitrous acid make feasible thermodynamically the domino reaction.

DFT calculations of the electrophilicity and nucleophilicity indexes in general agree with the experimental results and they are a good reactivity and regioselectivity predictors in this type of polar cycloaddition reactions

The presence of a PIL's in the reaction media improves significantly the electrophilic character of the dienophile. However, the differences between the experimental results using PIL's or molecular solvents are not so bigger how the calculated electrophilic values indicated. 


\section{Author details}

Pedro M. E. Mancini ${ }^{1 *}$, Carla M. Ormachea ${ }^{1}$, Claudia D. Della Rosa ${ }^{1}$, María N. Kneeteman ${ }^{1,2}$ and Luis R. Domingo ${ }^{3}$

*Address all correspondence to: pmancini@fiq.unl.edu.ar

1 Área de Química Orgánica-Departamento de Química-Facultad de Ingeniería QuímicaUniversidad Nacional del Litoral (UNL), Santa Fe, Argentina

2 Consejo Nacional de Investigaciones Científicas y Técnicas (CONICET), de la República Argentina

3 Departamento de Química Orgánica, Facultad de Química, Universidad de Valencia, España

\section{References}

[1] Arnó, M., \& Domingo, L. R. (2002). Density functional theory study of the mechanism of the proline-catalyzed intermolecular aldol reaction. Theoretical Chemistry Accounts, 108(4), 232-239.

[2] Biolatto, B., Kneeteman, M., Paredes, E., \& Mancini, P. M. E. (2001). Reactions of 1tosyl-3-substitutedindoles with conjugated dienes under thermal and/or hyperbaric conditions. Journal of Organic Chemistry, 66, 3906-3912, 0022-3263.

[3] Brasca, R., Kneeteman, M. N., Mancini, P. M. E., \& Fabian, W. M. F. (2011). Comprehensive DFT Study on Site-, Regio-, and Stereoselectivity of Diels-Alder Reactions Leading to 5 -Hydroxybenzofurans. Eur. J. Org. Chem, 721-729.

[4] Brasca, R., Kneeteman, M. N., Mancini, P. M. E., \& Fabian, W. M. F. Diels-Alder reactions for the rational design of benzo[b]thiophenes. DFT-based guidelines for synthetic chemists. Journal of Molecular Structure, THEOCHEM, 1010, 158.

[5] Brasca, R., Della Rosa, C., Kneeteman, M., \& Mancini, P. (2011). Five-membered aromatic heterocycles in polar cycloaddition reactions: theoretical studies as a complement of the experimental researches. Letters in Organic Chemistry, 8(2), 82-87.

[6] Brasca, R., Della Rosa, C., Kneeteman, M., \& Mancini, P. M. E. (2011). Five-Membered aromatic heterocycles in diels-alder cycloaddition reactions: Theoretical Studies as a Complement of the Experimental Researches. Letters in Organic Chemistry, 8(2), 82-87.

[7] Brasca, R., Kneeteman, M. N., Mancini, P. M. E., \& Fabian, W. M. F. (2009). Theoretical explanation of the regioselectivity of polar cycloaddition reactions between furan derivatives and Danishefsky's diene. Journal of Molecular Structure: THEOCHEM, 911(1-3), 124-131. 
[8] Brasca, R., Kneeteman, M. N., Mancini, P. M. E., \& Fabian, W. M. F. (2011). Comprehensive DFT study on site-, regio-, and stereoselectivity of diels-alder reactions leading to 5-hydroxybenzofurans. European Journal of Organic Chemistry, 4, 721-729.

[9] Cancian, S., Kneeteman, M., \& Mancini, P.M.E. (2010). Nitroquinolines as dienophiles in Polar Diels-Alder reactions. Influence of molecular solvent and ionic liquids. 14th International Electronic Conference on Synthetic Organic Chemistry (ECSOC-14), 0095-2338.

[10] Carruthers, W. (1990). Cycloaddition Reactions in Organic Synthesis, Pergamon Press, Oxford, UK.

[11] Corey, E.J. (2002). Catalytic enantioselective Diels-Alder reactions: methods, mechanistic fundamentals, pathways, and applications. Angew.Chem. Int. Ed., 41(10), 1650-67.

[12] Della Rosa, C., Ormachea, C., Kneeteman, M. N., Adam, C., \& Mancini, P. M. E. (2011). Diels-Alder reactions of N-tosylpirroles developed in protic ionic liquids. Theoretical studies using DFT methods. Tetrahedron Lett., 52, 6754-6757.

[13] Della Rosa, C., Sanchez, J.P., Kneeteman, M.N., \& Mancini, P.M.E. (2011). 2-Nitrobenzofuran and 3-Nitrobenzofurans as dienophiles in Polar Diels-Alder Reactions. A Simple Dibenzofurans Synthesis. Theoretical studies using DFT Methods. Tetrahedron Lett., 52, 2316-2319.

[14] Della Rosa, C., Kneeteman, M., \& Mancini, P. M. E. (2007). Behavior of selenophenes substituted with the electron withdrawing groups in polar Diels-Alder reactions. Tetrahedron Letters, 48, 7075-7078, 0040-4039.

[15] Della Rosa, C., Kneeteman, M., \& Mancini, P. M. E. (2007). Comparison of the reactivity between 2- and 3-nitropyrroles in cycloaddition reactions. A simple indole synthesis. Tetrahedron Letters, 48, 1435-1438, 0040-4039.

[16] Della Rosa, C. D., Sanchez, J. P., Kneeteman, M. N., \& Mancini, P. M. E. (2011). DielsAlder reactions of nitrobenzofurans: A simple dibenzofuran Synthesis. Theoretical studies using DFT methods. Tetrahedron Letters, 52(18), 2316-2319.

[17] Della Rosa, C., Kneeteman, M., \& Mancini, P. M. E. (2005). Nitrofurans as dienophiles in Diels-Alder reactions. Tetrahedron Letters, 46, 8711-8714, 0040-4039.

[18] Della Rosa, C., Paredes, E., Kneeteman, M., \& Mancini, P. M. E. (2004). Behavior of thiophenes substituted with electron-withdrawing groups in cycloaddition reactions. Letters in Organic Chemistry, 1, 148-150, 1687-6865.

[19] Della Rosa, C., Sanchez, J. P., Kneeteman, M., \& Mancini, P. M. E. (2010). Nitrobenzofuran as dienophile in Polar Diels-Alder reactions. A simple Dibenzofuran Synthesis. Journal of Chemistry and Chemical Engineering, 4(11), Serial 36, 54-59.

[20] Fringelli, F., \& Tatichi, A. (2002). The Diels-Alder Reaction, J. Wiley \& Sons, Chichester, UK. 
[21] Domingo, L. R. (2002). A density functional theory study for the Diels-Alder reaction between N-acyl-1-aza-1,3-butadienes and vinylamines. Lewis acid catalyst and solvent effects. Tetrahedron, 58(19), 3765-3774.

[22] Domingo, L. R., Arnó, M., Contreras, R., \& Pérez, P. (2002). Density functional theory study for the cycloaddition of 1,3-butadienes with dimethyl acetylenedicarboxylate. Polar stepwise vs concerted mechanisms. Journal of Physical Chemistry A, 106(6), 952-961.

[23] Domingo, L. R., \& José, Aurell M. (2002). Density functional theory study of the cycloaddition reaction of furan derivatives with masked o-benzoquinones. Does the furan act as a dienophile in the cycloaddition reaction. Journal of Organic Chemistry, 67(3), 959-965.

[24] Domingo, L. R., Chamorro, E., \& Pérez, P. (2008). An understanding of the electrophilic/nucleophilic behavior of electro-deficient 2,3-disubstituted 1,3-butadienes in polar Diels-Alder reactions. A density functional theory study. Journal of Physical Chemistry A, 112(17), 4046-4053.

[25] Hitchcock, P. B., Mohammed, T. J., Seddon, K. R., Zora, J. A., Hussey, C. L., \& Ward, E. H. (1986). 1-methyl-3-ethylimidazolium hexachlorouranate(IV) and 1-methyl-3ethylimidazolium tetrachlorodioxo-uranate(VI): Synthesis, structure, and electrochemistry in a room temperature ionic liquid. Inorganic Chimica Acta, 113, L25-L26, 19-191, 0020-1693.

[26] Jaramillo, P., Domingo, L. R., Chamorro, E., \& Pérez, P. (2008). A further exploration of a nucleophilicity index based on the gas-phase ionization potentials. Journal of Molecular Structure: THEOCHEM, 865(1-3), 68-72.

[27] Mancini, P. M. E., Fortunato, G., Bravo, M. V., \& Adam, A. (2012). Ionic Liquids:Binary Mixtures with Selected Molecular Solvents. Characterization of its Molecular-Microscopic Properties. Reactivity. Chapter 13, 335-362, in Green Solvents Book 2: Properties and Applications in Chemistry, Eds. Ali Mohammad and M.P. Inamuddin, 978-94-007-2890-5, 978-94-007-2891-2-eBook-, Springer, United Kingdom.

[28] Mancini, P. M. E., Kneeteman, M., Della Rosa, C., Bravo, V., \& Adam, C. (2011). Ionic Liquids in Polar Diels-Alder Reactions using Carbocycles and Heterocycles as Dienophiles. Ionic Liquid/Book 1. Ed. Scott Hardy, INTECH Open Access, cap. 13, 311-344, 978-953-308-66-6.

[29] Paredes, E., Brasca, R., Kneeteman, M., \& Mancini, P. M. E. (2007). A novel application of the Diels-Alder reaction: nitronaphthalene as normal electron demand dienophiles. Tetrahedron, 63, 3790-3799, 0040-4020.

[30] Parr, R. G., Szentpály, L. V., \& Liu, S. (1999). Electrophilicity index. Journal of the American Chemical Society, 121(9), 1922-1924. 
[31] Parr, R. G., \& Yang, W. (1984). Density functional approach to the frontier-electron theory of chemical reactivity. Journal of the American Chemical Society, 106(14), 4049-4050.

[32] Welton, T. (1999). Room-Temperature Ionic Liquids. Solvents for Synthesis and Catalysis. Chemical Review, 99(2071), 0010-8545. 
